\title{
Resolvin D1, Protectin D1, and Related Docosahexaenoic Acid-Derived Products: Analysis via Electrospray/Low Energy Tandem Mass Spectrometry Based on Spectra and Fragmentation Mechanisms
}

\author{
Song Hong, * Yan Lu,* Rong Yang, Katherine H. Gotlinger, \\ Nicos A. Petasis, ${ }^{+}$and Charles N. Serhan \\ Analytical Core, Center for Experimental Therapeutics and Reperfusion Injury, Department of \\ Anesthesiology, Perioperative and Pain Medicine, Brigham and Women's Hospital, Department of Oral \\ Medicine, Infection and Immunity, Harvard School of Dental Medicine, Harvard Medical School, Boston, \\ Massachusetts, USA
}

Resolvin D1 (RvD1) and protectin D1 (Neuroprotectin D1, PD1/NPD1) are newly identified anti-inflammatory lipid mediators biosynthesized from docosahexaenoic acid (DHA). In this report, the spectra-structure correlations and fragmentation mechanisms were studied using electrospray low-energy collision-induced dissociation tandem mass spectrometry (MS/MS) for biogenic RvD1 and PD1, as well as mono-hydroxy-DHA and related hydroperoxy-DHA. The loss of $\mathrm{H}_{2} \mathrm{O}$ and $\mathrm{CO}_{2}$ in the spectra indicates the number of functional group(s). Chain-cut ions are the signature of the positions and numbers of functional groups and double bonds. The observed chain-cut ion is equivalent to a hypothetical homolytic-segment (cc, cm, mc, or $\mathrm{mm}$ ) with addition or extraction of up to 2 protons $(\mathrm{H})$. The $\alpha$-cleavage ions are equivalent to: $[\mathrm{cc}+\mathrm{H}]$, with $\mathrm{H}$ from the hydroxyl through a $\beta$-ene or $\gamma$-ene rearrangement; [cm $-2 \mathrm{H}]$, with $2 \mathrm{H}$ from hydroxyls of PD1 through a $\gamma$-ene rearrangement, or $1 \mathrm{H}$ from the hydroxyl and the other $\mathrm{H}$ from the $\alpha$-carbon of mono-HDHA through an $\alpha$-H- $\beta$-ene rearrangement; [mc $-\mathrm{H}$ ], with $\mathrm{H}$ from hydroxyl through a $\beta$-ene or $\gamma$-ene rearrangement, or from the $\alpha$-carbon through an $\alpha$-H- $\beta$-ene rearrangement; or [mm] through charge-direct fragmentations. The $\beta$-ene or $\gamma$-ene facilitates the $\mathrm{H}$ shift to $\gamma$ position and $\alpha$-cleavage. Deuterium labeling confirmed the assignment of MS/MS ions and the fragmentation mechanisms. Based on the MS/MS spectra and fragmentation mechanisms, we identified RvD1, PD1, and mono-hydroxy-DHA products in human neutrophils and blood, trout head-kidney, and stroke-injury murine braintissue. (J Am Soc Mass Spectrom 2007, 18, 128-144) (c) 2007 American Society for Mass Spectrometry

$\mathrm{N}$ umerous reports demonstrate the beneficial effects of fish oil on human diseases such as arthritis, Alzheimer's disease, lung fibrosis, and inflammatory bowel diseases [1-3]. As an essential $\omega-3$ polyunsaturated fatty acid, docosahexaenoic acid (DHA) is a major component of fish oil [4]. Novel bioactive oxygenated DHA products biosynthesized in resolving inflammatory exudates and tissues were recently identified, and their structures and bioactions were elucidated [5-8]. They were named as the D series of resolvins

Published online October 19, 2006

Address reprint requests to Dr. C. N. Serhan, Harvard Medical School, Director, Center for Experimental Therapeutics and Reperfusion Injury, Brigham and Women's Hospital, Thorn Building for Medical Research, 7th floor, 75 Francis Street, Boston, MA 02115. E-mail: cnserhan@ zeus.bwh.harvard.edu

* Share first authorship, contributing equally to this manuscript.

† Department of Chemistry and the Loker Hydrocarbon Research Institute, University of Southern California, Los Angeles, California, USA (resolution phase interaction products) and protectins (protecting brain and other organs against inflammatory diseases) because their biosynthetic pathways display potent anti-inflammatory and immunoregulatory properties (Scheme 1)[5-9]. As illustrated in Scheme 1, DHA is initially converted to 17S-hydroperoxy-DHA (HpDHA), then further enzymatically transferred to resolvin D1(RvD1) and protectin D1 (neuroprotectin D1, PD1/ NPD1) via epoxide intermediates. With aspirin treatment, the aspirin-acetylated cyclooxygenase type II (COX-2) converts DHA into 17R-HpDHA, which is further converted to 17R-RvD1 and 17R-PD1 [5].

To obtain the temporal and spatial profiles and regulation of biosynthesis of RvD1 and PD1 as well as other DHA products during physiopathological processes, their identification needs to be accurate, sensitive, and fast. One suitable approach is liquid chromatography coupled to an ultraviolet spectrometer and a 


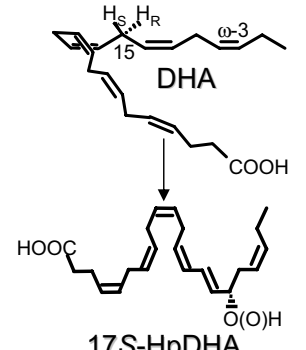

17S-HpDHA

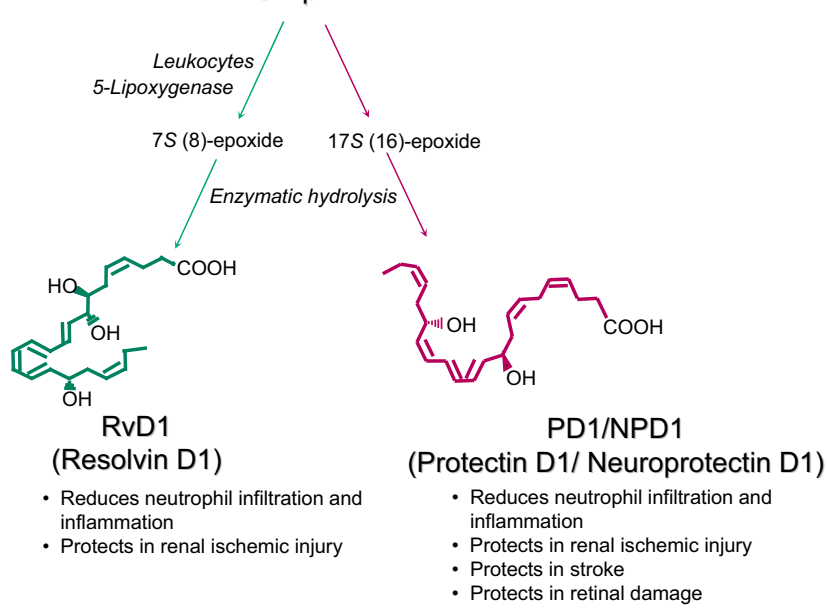

Scheme 1. Biosynthetic pathways for Resolvin D1 (RvD1) and Protectin D1 (PD1).

low collision-energy tandem mass spectrometer (LCUV-MS/MS) with atmospheric pressure ionization, specifically electrospray ionization (ESI) [5-8]; this is used on full product ion scan bases for structure elucidation and identification of resolvins and protectins at low nanogram levels [5-8]. Authentic standards of resolvins and protectin D1 prepared via total organic synthesis are used for confirmation during the identification. The low levels (under a few nanograms/sample) of these mediators present in vivo make other instrumentation, such as nuclear magnetic resonance or optical spectrometers, inappropriate for the analysis. In comparison, different types of mass spectrometry were used in the earlier studies of DHA-derived products. These included gas chromatography-MS with electronimpact ionization used by Van Rollins and Murphy and coworkers to analyze the structures of mono-hydroxyDHA products after silanization and methylation [9]. Kim and Salem conducted preparation and structure analysis of HDHAs and HpDHAs using LC-positive ion thermospray MS/MS [10]. They also developed an analytical method and conducted stereochemistry studies of all the HDHAs produced by human platelets and rat brain homogenates using chiral LC-thermospray-MS and GC/MS (electron-impact ionization) [11].

Low-energy ionization primarily generates molecular (or pseudo-molecular) ions for collision-induced dissociation (CID) MS/MS analysis, through which the MS/MS spectra obtained are used widely to identify and elucidate the structures of lipid mediators derived from polyunsaturated fatty acids [12-20]. The lowenergy CID of eicosanoids includes charge-remote and charge-directed fragmentations $[12,21]$, many of which occur through " $\alpha$-hydroxy- $\beta$-ene like rearrangement" as referred to by Murphy, i.e., $\alpha$-cleavage of the carbon-carbon bond ( $\alpha$ position to hydroxy group), facilitated by a double bond (ene) in the $\beta$ position [22]. For polyunsaturated fatty acids and their derivatives, ions formed in low-energy CID MS/MS via the loss of only $\mathrm{H}_{2} \mathrm{O}$ and $\mathrm{CO}_{2}$ are usually much more abundant than ions formed through cleavage of the carbon chain. In this report, the former are called "peripheral-cut ions" and the latter are called "chain-cut ions." Peripheral-cut ions provide information about the number of hydroxys and carboxylates in a compound; chaincut ions are the signatures for the positions of hydroxys and double bonds. The ions formed via a combination of chain-cut and peripheral-cut processes are called "chainplus-peripheral-cut" ions [23]. The structure of a compound is deduced from the integration of the structures assigned to its MS/MS ions. Thus, the fragmentation mechanisms for the formation of MS/MS ions are very important for the identification using the MS/MS ions of a novel and/or known molecular structure. These mechanisms form the basis for lipidomic databases, which consist of lipid mass spectra and other analytical data, and search algorithms [23].

Here, we report the analysis of resolvin D1 and protectin D1, as well as other DHA-derived products without derivatization, using low-collision-energy tandem mass spectra acquired on anions generated from electrospray ionization of molecules eluted from LC. For structure elucidation and identification, the ion structures and MS/MS fragmentation mechanisms are proposed and confirmed via deuterium-labeled isotopomers of these compounds. RvD1 and PD1, as well as mono-hydroxy-DHA products, were found to be generated by human neutrophils, whole blood [6], trout head-kidney [25], and stroke-injury murine brain tissues [7], ${ }^{\circ}$ using $^{\circ}$ this ${ }^{\circ}$ LC-UV-MS/MS ${ }^{\circ}$ approach.

\section{Experimental}

\section{Instrumentation}

The MS/MS spectrum was acquired on each chromatographic peak eluted from a column of a LC-UV-MS/MS system. This system includes a HPLC (P4000) coupled to a photo-diode-array UV detector and an ion trap (LCQ) MS/MS (Thermoelectron, San Jose, CA). Approximately $10 \mathrm{ng}$ of each authentic standard were injected individually into the column (LUNA C18-2 150 $\mathrm{mm} \times 2 \mathrm{~mm} \times 5 \mathrm{~m}$, Phenomenex, Torrance, $\mathrm{CA}$ ), which was eluted at $0.2 \mathrm{ml} / \mathrm{min}$ and $23^{\circ} \mathrm{C}$. The mobile phase flowed as C (water:methanol:acetic acid $=65 \%: 35 \%$ : $0.01 \%$ ) from 0 to $50 \mathrm{~min}$; ramped to $100 \%$ methanol from 50.1 to 110 mins; maintained as $100 \%$ methanol for 10 mins, then back to $\mathrm{C}$. The UV detector scanned from 200 to $400 \mathrm{~nm}$, providing additional spectral confirma- 
tion to ensure the purity of the authentic standards. For RvD1, PD1, mono-hydroxy-DHAs (HDHAs), and HpDHA, the maximum UV absorption wavelengths are $301 \mathrm{~nm}, 270 \mathrm{~nm}$, and $235 \mathrm{~nm}$, respectively. Conditions for the mass spectrometer are: electrospray voltage, 4.3 $\mathrm{kV}$; heating capillary, $-39 \mathrm{~V}$; tube lens offset, $60 \mathrm{~V}$; sheath $\mathrm{N}_{2}$ gas, $1.2 \mathrm{~L} / \mathrm{min}$; and auxiliary $\mathrm{N}_{2}$ gas, 0.045 $\mathrm{L} / \mathrm{min}$; collision energy was 35 to $45 \%$ (a relative collision energy of 0 to $100 \%$ corresponds to a highfrequency alternating voltage for resonance excitation from 0 to $5 \mathrm{~V}$ maximum); helium gas, $0.1 \mathrm{~Pa}$ as a collision ${ }^{\circ}$ gas $^{\circ}{ }^{\circ}$ and $^{\circ}$ scan $^{\circ}$ range, $^{\circ} \mathrm{m} / \mathrm{z} 9^{\circ}$ to $^{\circ} 390^{\circ}$ [23] .

\section{Materials and Sample Preparation}

Biogenic syntheses of RvD1, 17S-HDHA, and 17-HpDHA were conducted via incubation of DHA (Cayman Chemical, ${ }^{\circ}$ Ann ${ }^{\circ}$ Arbor, 9 MI) $\lceil\text { 5, 6, } 24]^{\circ}$ with isolated ${ }^{\circ}$ inzyme(s), i.e., soybean 15-lipoxygenase and/or potato 5-lipoxygenase (Sigma Co., St. Louis, MO). Following the same procedures but replacing DHA with $\mathrm{d}_{5}$-DHA $\left(21,21,22,22,22-\mathrm{d}_{5}-\right.$ DHA) (Cayman Chemical), we prepared $d_{5}-R_{D} 1, d_{5^{-}}$ PD1, $\mathrm{d}_{5}-17 \mathrm{~S}-\mathrm{HDHA}$, and $\mathrm{d}_{5}-17-\mathrm{HpDHA}$, and acquired their spectra and chromatograms on LC-UV-MS/MS. The structures of biogenically synthesized RvD1 and PD1 were further confirmed via matching the spectra of MS/MS and UV (coupled to a LC), GC/MS, and chromatographic retention times of RvD1 and PD1, which were ${ }^{\circ}$ prepared by $^{\circ}$ total ${ }^{\circ}$ organic ${ }^{\circ}$ synthesis $[24,26]$. ${ }^{\circ}$ HDHAs were purchased from Cayman Chemical. All other reagents were from available commercial sources at the highest grade.

Some of the deuterium-labeled compounds were obtained via deuterium-exchange of labile hydrogens in the hydroxy(s) and carboxylate, which include $\mathrm{O}, \mathrm{O}, \mathrm{O}, \mathrm{O}-\mathrm{d}_{4}$ $\mathrm{RvD1}, \mathrm{O}, \mathrm{O}, \mathrm{O}, 21,21,22,22,22-\mathrm{d}_{8}-\mathrm{PD} 1$ (from deuterium exchange of labile hydrogens in the two hydroxys and one carboxylate of $\left.\mathrm{d}_{5}-\mathrm{PD} 1\right), \mathrm{O}, \mathrm{O}, \mathrm{O}-\mathrm{d}_{3}-\mathrm{PD} 1$, and $\mathrm{O}, \mathrm{O}-\mathrm{d}_{2}-$ HDHAs. The deuterium-exchange was achieved when the samples were analyzed on LC-UV-MS/MS using the same gradient as described above except substituting $\mathrm{MeOD}, \mathrm{D}_{2} \mathrm{O}$, and d-acetic acid for methanol, water, and acetic acid, respectively.

Samples of human whole blood (venous) and PMN were $^{\circ}$ obtained $^{\circ}$ and $^{\circ}$ prepared $^{\circ}$ as $^{\circ}$ described $^{\circ}$ elsewhere ${ }^{\circ}[6]$. Stroke-injury murine brain tissues were provided by Professor N. Bazan's group at Louisiana State University Health Sciences Center. The surgery procedures and sample ${ }^{\circ}$ preparation ${ }^{\circ}$ have $^{\circ}$ also $^{\circ}$ been $^{\circ}$ described $^{\circ}[7] .^{\circ}$ Samples $^{\circ}$ of trout ${ }^{\circ}$ rain ${ }^{\circ}$ and head-kidney ${ }^{\circ}$ were ${ }^{\circ}$ prepared ${ }^{\circ}{ }^{\circ}$ in $^{\circ}[25] .{ }^{\circ}$ All samples were added with two volumes of cold methanol [6]. ${ }^{\circ}$ Briefly, ${ }^{\circ}$ this ${ }^{\circ}$ procedure $^{\circ}$ is $^{\circ}$ tailored $^{\circ}$ as $^{\circ}$ follows. ${ }^{\circ}$ The samples were centrifuged ( $\left.3000 \mathrm{rpm}, 4^{\circ} \mathrm{C}, 15 \mathrm{~min}\right)$ to remove cellular and protein materials. After the supernatants were decanted, they were diluted with 10 volumes of water purified with the Milli-Q System (Millipore, Billerica, MA). The $\mathrm{pH}$ was adjusted to 3.5 with $1 \mathrm{M} \mathrm{HCl}$ for C18 solid-phase extraction (SPE). After a wash with $15 \mathrm{ml}$ of $\mathrm{H}_{2} \mathrm{O}$ and then $8 \mathrm{ml}$ of hexane, the SPE cartridges (C18,
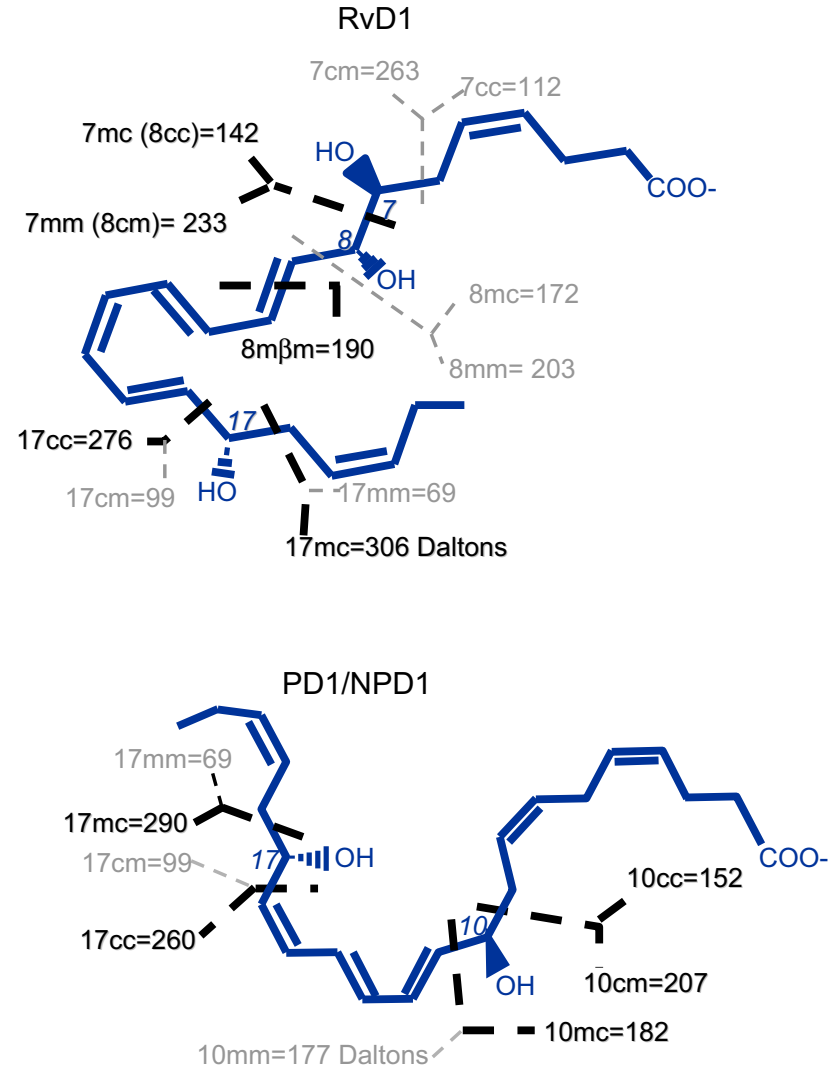

Scheme 2. Naming hypothetic-homolytic-segments of lipid mediators with RvD1 and PD1/NPD1 as an example.

$3 \mathrm{ml}$, Waters, Millford, MA) were eluted with $8 \mathrm{ml}$ of methyl formate, and the effluent was reconstituted into methanol for lipidomic analysis using LC-UV-MS/MS.

\section{Nomenclature}

To illustrate the interpretation of MS/MS ions generated from RvD1, PD1/NPD1, and other related DHA-derived products, we use the nomenclature'recently proposed [23] to name the specific "segments", which are fragments formed through hypothetic homolytic cleavages without hydrogen or group migration. This is depicted in Scheme 2 using RvD1 and PD1 structures. A number is used to designate the position of a hydroxy or another functional group on the carbon-chain where the cleavage occurs. The letter immediately following the number indicates the side of the functional group on which the cleavage occurs: " $c$ " is for cleavage on the carboxyl side of the functional group and " $\mathrm{m}$ " is for cleavage on the methyl side of the functional group. Each cleavage can directly generate two segments. The second letter indicates the side of the cleavage on which the segment forms: " $c$ " is for a segment formed on the carboxyl side of the cleavage and " $\mathrm{m}$ " is for a segment formed on the methyl side of the cleavage. Segments formed through $\beta$-cleavage or $\gamma$-cleavage along the functional group are named by adding $\beta$ or $\gamma$ between the otwo "c" / "m" "letters"[23]. 

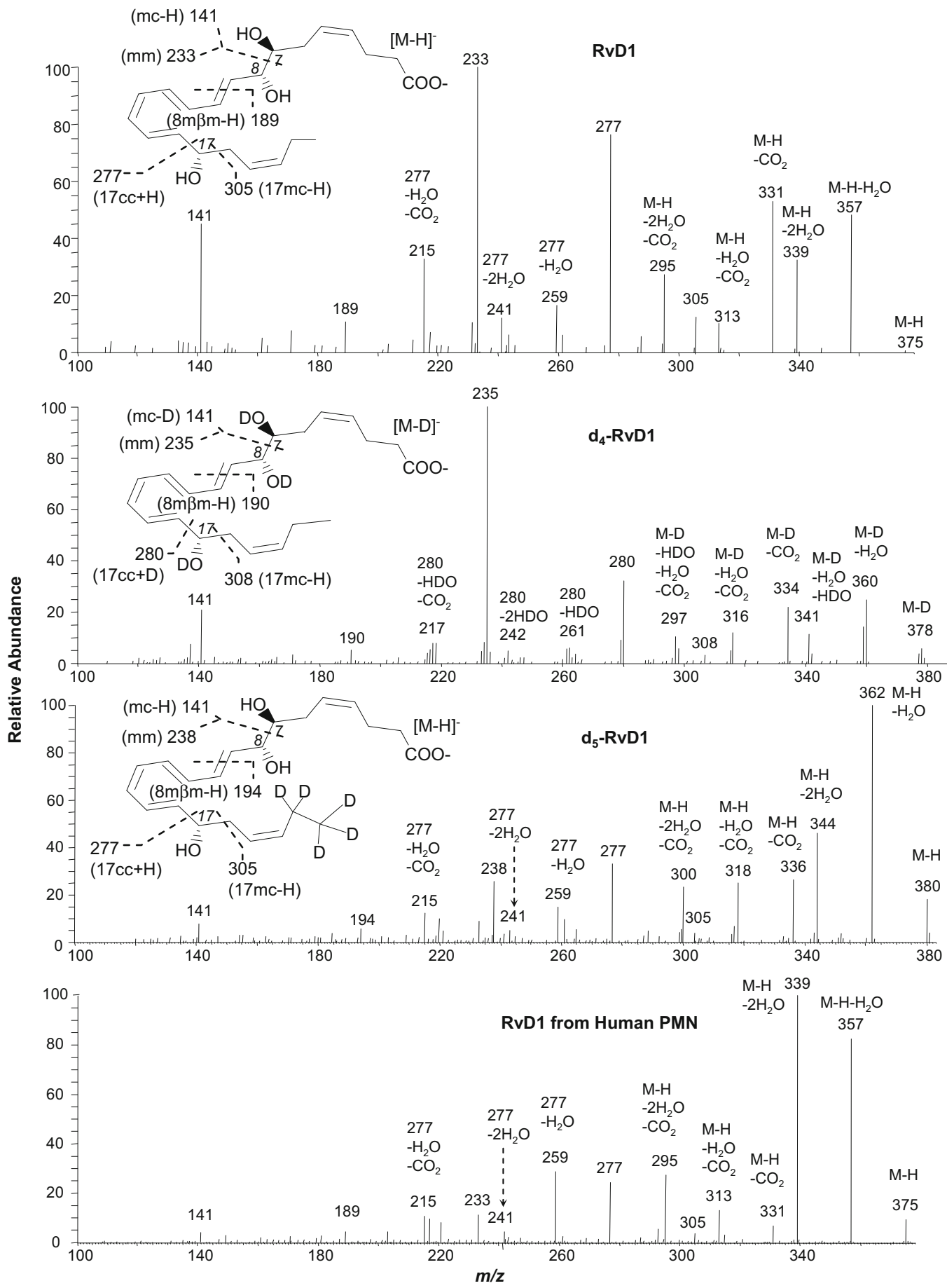

Figure 1. Low-energy MS/MS spectra acquired via CID of the electrospray-generated carboxylate anion $[\mathrm{M}-\mathrm{H} \text { or }]^{-}$from the LC peak of resolvin D1 or deuterated RvD1. RvD1, O,O,O,O- $\mathrm{d}_{4}-\mathrm{RvD} 1$, and 21,21,22,22,22- $\mathrm{d}_{5}-\mathrm{RvD} 1$ were obtained from isolated-enzyme reactions with or without deuteriumexchange, as well as from human PMN, as detailed in the Experimental section. Each inset depicts the structure and CID fragmentation.

\section{Results}

The electrospray ionization in negative mode generated primarily deprotonated molecular ions $[\mathrm{M}-\mathrm{H} \text { or } \mathrm{D}]^{-}$ from resolvin D1 (Figure 1), protectin D1, other related DHA-derived compounds, and their deuterium isotopomers eluted from the LC column. In MS/MS exper- iments, $[\mathrm{M}-\mathrm{H}]^{-}$ions were selected and fragmented via CID. Cleavage on the carbon chain was frequently observed on the $\alpha$ locations toward hydroxy and hydroperoxy. This is similar to the CID fragmentation of derivatives from arachidonic acid and eicosapentaenoic acid $[5,6,13,27]$. 

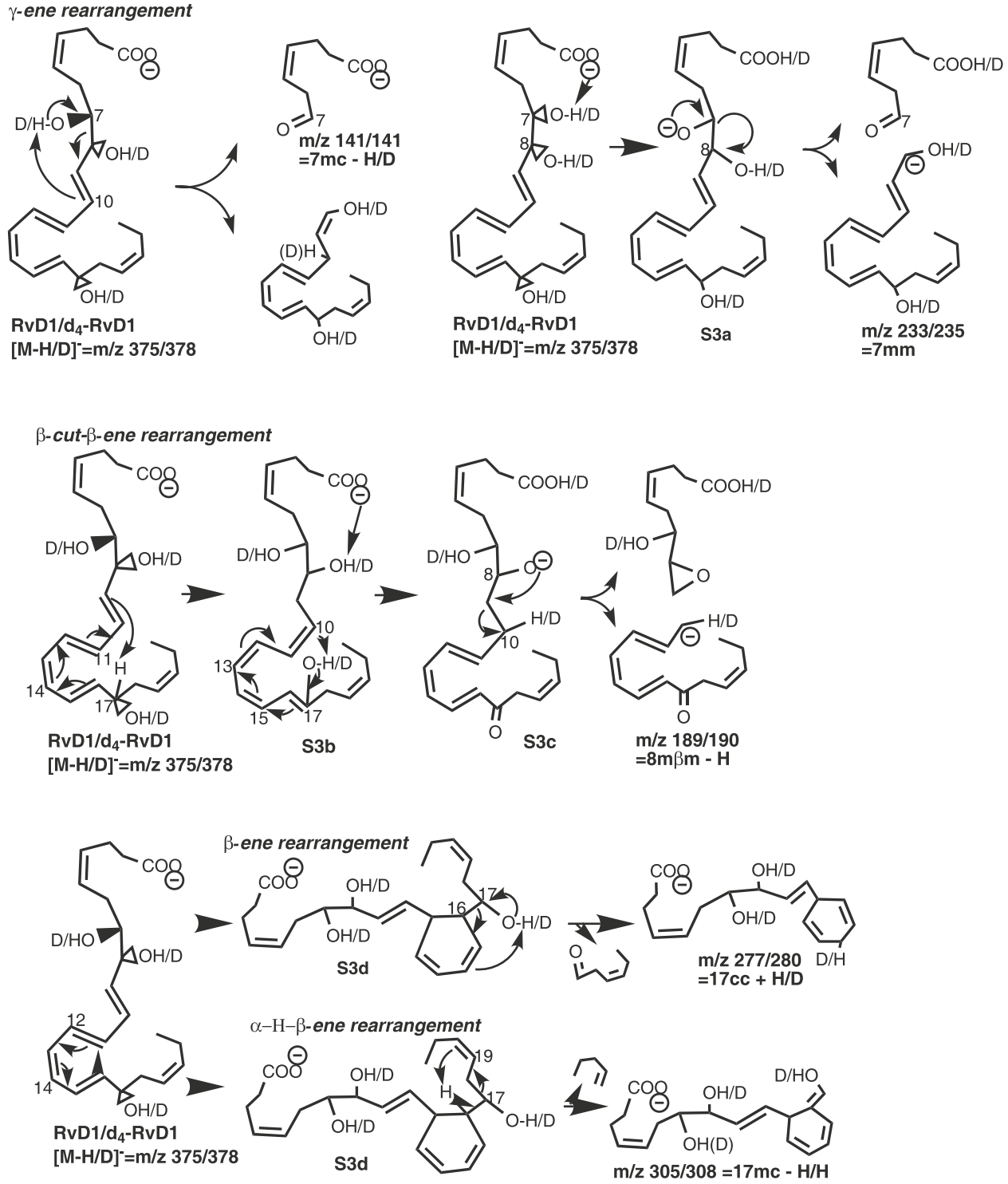

Scheme 3. Fragmentation mechanisms for RvD1/d4-RvD1 ([M-H/D] $]^{-}=m / z$ 375/378).

$R v D 1, O, O, O, O-d_{4}-R v D 1$, and $21,21,22,22,22-d_{5^{-}}$ RvD1 (Figure 1 and Scheme 3).

RvD1 is 7S,8R,17S-trihydroxy-docosa-4Z,9E,11E,13Z,15E, 19Z-hexaenoic acid, which has three hydroxy groups and six double bonds, four of which are conjugated and bracketed by the 8-hydroxy and 17-hydroxy (see inset of Figure 1). The low collision-energy MS/MS spectrum of the LC peak of the RvD1 shows peripheral-cut ions at $\mathrm{m} / \mathrm{z}$ $357\left[\mathrm{M}-\mathrm{H}-\mathrm{H}_{2} \mathrm{O}\right]$ (relative intensity is $47 \%$ ), 339 [M $\left.\mathrm{H}-2 \mathrm{H}_{2} \mathrm{O}\right](32 \%), 331\left[\mathrm{M}-\mathrm{H}-\mathrm{CO}_{2}\right](52 \%), 313[\mathrm{M}-\mathrm{H}$ $\left.-\mathrm{H}_{2} \mathrm{O}-\mathrm{CO}_{2}\right](10 \%)$, and $295\left[\mathrm{M}-\mathrm{H}-2 \mathrm{H}_{2} \mathrm{O}-\mathrm{CO}_{2}\right](26 \%)$ (Figure 1). The assignment of these ions is consistent with $\mathrm{O}, \mathrm{O}, \mathrm{O}, \mathrm{O}-\mathrm{d}_{4}-\mathrm{RvD} 1\left(\mathrm{~d}_{4}-\mathrm{RvD} 1\right)$, ions: $360\left[\mathrm{M}-\mathrm{D}-\mathrm{H}_{2} \mathrm{O}\right]$ $(27 \%), 341$ [M - D - $\left.\mathrm{H}_{2} \mathrm{O}-\mathrm{HDO}\right](14 \%), 334$ [M - D $\left.\mathrm{CO}_{2}\right](22 \%), 316\left[\mathrm{M}-\mathrm{D}-\mathrm{H}_{2} \mathrm{O}-\mathrm{CO}_{2}\right](14 \%)$, and $297[\mathrm{M}-$ $\left.\mathrm{D}-\mathrm{HDO}-\mathrm{H}_{2} \mathrm{O}-\mathrm{CO}_{2}\right](12 \%) ; 21,21,22,22,22-\mathrm{d}_{5}-\mathrm{RvD} 1\left(\mathrm{~d}_{5}-\right.$ RvD1) ions: 362 [M - $\left.\mathrm{H}-\mathrm{H}_{2} \mathrm{O}\right](100 \%), 344$ [M - H $\left.2 \mathrm{H}_{2} \mathrm{O}\right](46 \%), 336\left[\mathrm{M}-\mathrm{H}-\mathrm{CO}_{2}\right](27 \%), 318[\mathrm{M}-\mathrm{H}-$
$\left.\mathrm{H}_{2} \mathrm{O}-\mathrm{CO}_{2}\right](25 \%)$, and $300\left[\mathrm{M}-\mathrm{H}-2 \mathrm{H}_{2} \mathrm{O}-\mathrm{CO}_{2}\right](24 \%)$; and $\mathrm{d}_{4}-\mathrm{RvD} 1$ also possesses ions 359 [M - D - HDO] $(14 \%), 342\left[\mathrm{M}-\mathrm{D}-2 \mathrm{H}_{2} \mathrm{O}\right](4 \%), 315[\mathrm{M}-\mathrm{D}-$ $\left.\mathrm{HDO}-\mathrm{CO}_{2}\right](8 \%)$, and $298\left[\mathrm{M}-\mathrm{D}-2 \mathrm{H}_{2} \mathrm{O}-\mathrm{CO}_{2}\right](8 \%)$. These peripheral-cut ions support the existence of the carboxyl group (for $\mathrm{CO}_{2}$ loss) and hydroxy groups (for $\mathrm{H}_{2} \mathrm{O}$ loss) in RvD1. However, these ions do not provide the specific information or clues for the positions of the hydroxy(s) and double bonds. The loss of $\mathrm{H}_{2} \mathrm{O}$ from $\mathrm{d}_{4}-\mathrm{RvD} 1$, whose hydroxy hydrogens were completely deuterated, indicates that the deuteroxy deuterium is exchanged with the carbonchain-bonded hydrogen. The chain-cut MS/MS ions of RvD1 are as follows: some of them further transfer to chain-plus-peripheral-cut ions via loss of water or $\mathrm{CO}_{2}$. Chain-cut and chain-plus-peripheral-cut ions provide the signatures for the positions of functional groups and double bonds. 
The ion $m / z 141$ (44\%) of RvD1 is equal to segment 7 mc minus the 7-hydroxy proton $(\mathrm{H}$ from $7-\mathrm{OH}$ or $7-\mathrm{OH}$ $\mathrm{H})$, namely [7 mc - $\mathrm{H}$ from $7-\mathrm{OH}]$ corresponding to the following mechanism (Scheme 3). When the $7-\mathrm{OH} \mathrm{H}$ is extracted, through a transit six-membered ring, to C10 by the double bond $\mathrm{C} 9,10$, which is at $\gamma$ position to 7-OH, 7-OH converts to a carbonyl group, the allylic single bond $\mathrm{C} 7,8$ at $\alpha$ position to $7-\mathrm{OH}$ cleaves, and the C8,9 double bond forms, yielding ion $m / z 141$ and an enol. We refer to such process having $\gamma$-ene facilitated $\alpha$-OH H migration and $\alpha$-cleavage as a " $\gamma$-ene rearrangement." The mechanism was confirmed by ion $\mathrm{m} / \mathrm{z}$ 141 as [7 mc - deuteron from 7-deuteroxy] (i.e., [7 mc $\mathrm{D}$ from 7-OD]) from $\mathrm{d}_{4}-\mathrm{RvD} 1$ and as [7 $\mathrm{mc}-\mathrm{H}$ from 7-OH] from $\mathrm{d}_{5}-\mathrm{RvD}_{1}$.

In competition with the formation of ion $m / z 141$, 7-OH H shifts to the carboxyl anion internally, forming 7-alkoxide anion S3a. The negative charge of S3a directs the cleavage of $\mathrm{C} 7,8$ allylic single bond at $\alpha$ position, resulting in ion $m / z 233(100 \%)$ [corresponding to ions $\mathrm{m} / \mathrm{z} 235(100 \%)$ for $\mathrm{d}_{4}$-RvD1 and $238(26 \%)$ for $\left.\mathrm{d}_{5}-\mathrm{RvD} 1\right]$ (Figure 1), which is equivalent to segment [7 $\mathrm{mm}$ ]. Additionally, the deuterium labeling on C21 and C22 of $\mathrm{d}_{5}$-RvD1 changed the base-peak from ion $\mathrm{m} / \mathrm{z} 233$ of RvD1 or $m / z 235$ (equivalent to [7 mm]) of $\mathrm{d}_{4}-\mathrm{RvD1}$ to ion $m / z 362\left[\mathrm{M}-\mathrm{H}-\mathrm{H}_{2} \mathrm{O}\right]$.

Ion $m / z 189$ is equal to [ $8 \mathrm{~mm}-\mathrm{H}$ ] for RvD1, which is equivalent to ion $m / z 190[8 \mathrm{~m} \beta \mathrm{m}-\mathrm{H}]$ for $\mathrm{d}_{4}-\mathrm{RvD} 1$. Their formation corresponds to the following mechanism. Initially, $\mathrm{H}$ from $\mathrm{C} 17$ of the parent ion is extracted to $\mathrm{C} 9$ by $\mathrm{C} 9,10$ double bond at $\beta$ position to $8-\mathrm{OH}$ and the conjugated tetraene $\Delta 9,11,13,15$ converts to $\Delta 10,12,14,16$ in S3b. When $17-\mathrm{OH} H$ (or D 17-OD D) moves to $\mathrm{C} 10$, this tetraenol $\mathrm{S} 3 \mathrm{~b}$ changes to tetraenone S3c; meanwhile, the 8-OH H (or 8-OD D for $\mathrm{d}_{4}$ - $\mathrm{RvD1}$ ) migrates to the carboxylate anion, resulting in the 8 -alkoxide anion S3c. Then the negative charge of the S3c directs the breakage of the $C 9,10$ allylic single bond at the $\beta$ position to the 8 -alkoxide group, yielding ion $m / z 189$ (14\%) from RvD1, m/z 190 (6\%) from d $\mathrm{d}_{4}$-RvD1, and $m / z 194(7 \%)$ from $d_{5}-R v D 1$. We refer to such process with $\beta$-cleavage facilitated by $\alpha-\mathrm{OH}$ and $\beta$-ene as a " $\beta$-cut- $\beta$-ene rearrangement."

Ion $m / z 277$ (75\%) of RvD1 and ion $m / z 280$ (32\%) of $\mathrm{d}_{4}-\mathrm{RvD} 1$ are equivalent to $[17 \mathrm{cc}+\mathrm{H}$ from $17-\mathrm{OH}]$ and [17 cc + D from 17-OD], respectively. They correspond to the $\alpha$-cleavage of the $\mathrm{C} 16,17$ bond of their parent ions, of which the $\beta$ double bond $C 15,16$ facilitates the cleavage. This is a typical $\alpha$-hydroxy- $\beta$-ene-like rearrangement (abbreviated as $\beta$-ene rearrangement) [22]. When the conjugated triene $\Delta 11,13,15$ of the parent ion forms a six-membered ring in S3d, the $\beta$ double bond $\mathrm{C} 15,16$ shifts to $\gamma$ position, forming a C14,15 double bond, and the vinyl single bond C16,17 becomes the allylic single bond $\mathrm{C} 16,17$ in S3d. Then the $17-\mathrm{OH} \mathrm{H}$ (or 7-OD D in $\mathrm{d}_{4}$-RvD1) shifts to C14 of the $\gamma$ double bond C14,15, a 17-carbonyl group forms, and the C16,17 allylic single bond cleaves, producing ion $m / z 277$ of RvD1 and $\mathrm{d}_{5}-\mathrm{RvD} 1$ [or 280 of $\mathrm{d}_{4}$-RvD1]. Thus, this $\beta$-ene rearrangement includes conversion of $\beta$-ene to $\gamma$-ene and $\alpha$ vinyl single bond to $\alpha$ allylic single bond, and subsequently the $\gamma$-ene rearrangement, similar to the case of the ion $m / z 141$ from RvD1 discussed above.

When the C16-proton (H) in S3d shifts to C20, instead of the shift of $\mathrm{H}$ from $17-\mathrm{OH}$ to $\mathrm{C} 20$ (which would have generated ion $m / z 307$ for $d_{5}-R v D 1$ ), the C17,18 allylic single bond fragments, yielding ion $\mathrm{m} / \mathrm{z}$ 305 (11\%, equivalent to [17 mc - H from C16]) from RvD1. This mechanism is confirmed by ion $m / z 308$ (5\%) from $\mathrm{d}_{4}-\mathrm{RvD1}$ (Scheme 3) and ion $\mathrm{m} / \mathrm{z} 305$ (6\%) from $\mathrm{d}_{5}$-RvD1. We refer to this process as " $\alpha$-H- $\beta$-ene rearrangement."

The 17-OH in S3d is competitively deprotonated internally by its carboxyl anion to form a C17-alkoxide anion, of which the negative charge directs the breakage of $\mathrm{C} 16,17$ allylic single bond, generating ion $\mathrm{m} / \mathrm{z} 277$; similar to that discussed for S3d above, a charge-remote process for this alkoxide anion, also involving the migration of $\mathrm{C} 16-\mathrm{H}$ to $\mathrm{C} 20$, cleaves allylic single bond $\mathrm{C} 17,18$ and generates ion $m / z 305$ [12] (Scheme 3). This is also an $\alpha-\mathrm{H}-\beta$-ene rearrangement. The $\alpha-\mathrm{H}$ is less active than $\mathrm{H}$ from $\alpha-\mathrm{OH}$ because the $\mathrm{C}-\mathrm{H}$ bond is much less polarized than the $\mathrm{O}-\mathrm{H}$ bond; thus the abundance of ion $\mathrm{m} / \mathrm{z} 277$ is higher than that of ion $\mathrm{m} / \mathrm{z}$ 305 for RvD1 and $d_{5}-\operatorname{RvD} 1$. The same pattern is observed: ion $m / z 280$ is more abundant than ion $m / z 308$ for $\mathrm{d}_{4}-\mathrm{RvD} 1$, and ion $m / z 277$ is more abundant than ion $m / z 305$ for $\mathrm{d}_{5}$ RvD1.

The loss of water and/or $\mathrm{CO}_{2}$ generated ions 259 [277 - $\mathrm{H}_{2} \mathrm{O}$ ] for $\mathrm{RvD} 1(15 \%)$ and $\mathrm{d}_{5}-\mathrm{RvD} 1(16 \%), 241$ [277 $-2 \mathrm{H}_{2} \mathrm{O}$ ] for RvD1 (11\%) and $\mathrm{d}_{5}-\mathrm{RvD} 1$ (6\%), 215 [277 $\mathrm{H}_{2} \mathrm{O}-\mathrm{CO}_{2}$ ] for $\mathrm{RvD} 1$ (32\%) and $\mathrm{d}_{5}-\mathrm{RvD} 1$ (15\%), and 217 [280 - $\mathrm{HDO}-\mathrm{CO}_{2}$ ] (7\%) for $\mathrm{d}_{4}-\mathrm{RvD} 1$, which further confirmed the structure assignment of ion $\mathrm{m} / \mathrm{z} 277$. Using this LC-UV-MS/MS analysis, RvD1 was found to be biosynthesized by human neutrophils. The MS/MS spectrum of a chromatographic peak acquired from the samples of human neutrophils matches the spectrum of standard RvD1 (bottom panel, Figure 1), as do the UV spectrum and chromatographic retention time (data not shown).

$P D 1, O, O, O-d_{3}-P D 1,21,21,22,22,22-d_{5}-P D 1$, and $O, O, O, 21,21,22,22,22-d_{8}-P D 1$ (Figure 2 and Scheme 4).

Among the six double bonds of PD1 (protectin D1/neuroprotectins D1: 10R,17S-dihydroxy-docosa4Z,7Z,11E,13E,15Z,19Z-hexaenoic acid), three are conjugated between $10-\mathrm{OH}$ and $17-\mathrm{OH}$ (see Figure 2 inset). Negative electrospray ionization generated ion $\mathrm{m} / \mathrm{z} 359$, a deprotonated molecular ion $[\mathrm{M}-\mathrm{H}]^{-}$, from PD1. The MS/MS spectrum at $m / z 359$ of PD1 from trout headkidney matches to that acquired from synthetic PD1 (see Figure 1 of reference [25]). There are peripheral-cut ions at $m / z$ of $341\left[\mathrm{M}-\mathrm{H}-\mathrm{H}_{2} \mathrm{O}\right](100 \%), 323[\mathrm{M}-\mathrm{H}-$ $\left.2 \mathrm{H}_{2} \mathrm{O}\right](20 \%), 315\left[\mathrm{M}-\mathrm{H}-\mathrm{CO}_{2}\right](29 \%), 297[\mathrm{M}-\mathrm{H}-$ 


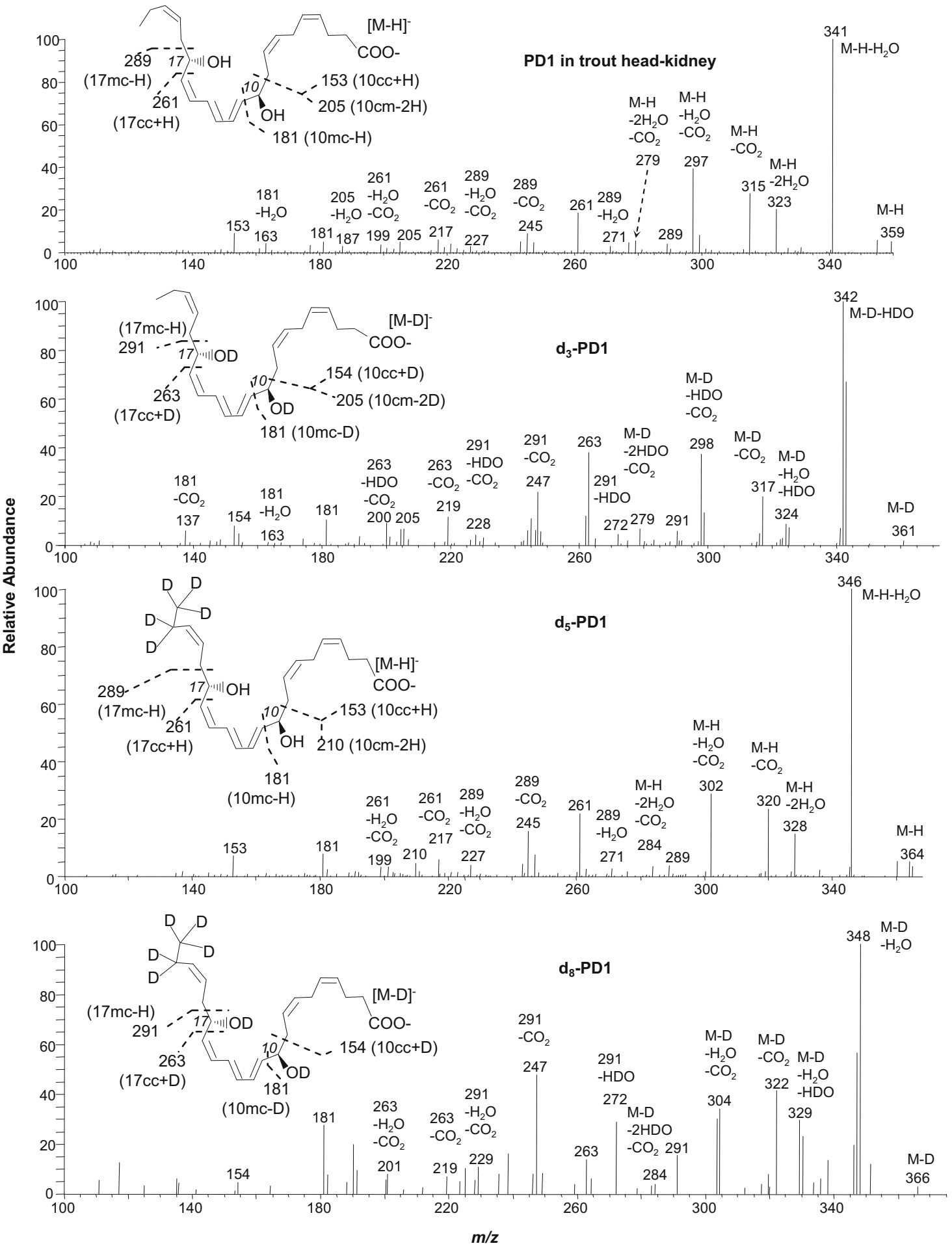

Figure 2. Low-energy MS/MS spectra acquired via CID of electrospray-generated carboxylate anion $[\mathrm{M}-\mathrm{H} \text { or } \mathrm{D}]^{-}$from the LC peak of PD1 or deuterated PD1. PD1 was obtained from trout head kidney; $\mathrm{O}, \mathrm{O}, \mathrm{O}-\mathrm{d}_{3}-\mathrm{PD} 1,21,21,22,22,22-\mathrm{d}_{5}-\mathrm{PD} 1$, and $\mathrm{O}, \mathrm{O}, \mathrm{O}, 21,21,22,22,22-\mathrm{d}_{8}-\mathrm{PD} 1$ were obtained from isolated-enzyme reactions with or without deuterium-exchange, as detailed in the Experimental section. Each inset depicts the structure and CID fragmentation.

$\left.\mathrm{H}_{2} \mathrm{O}-\mathrm{CO}_{2}\right](39 \%)$, and $279\left[\mathrm{M}-\mathrm{H}-2 \mathrm{H}_{2} \mathrm{O}-\mathrm{CO}_{2}\right](7 \%)$, consistent with the PD1 structure of one carboxylic group and two hydroxy groups. These ions are equivalent to those at $m / z 342$ [M - D - HDO] (100\%), 324
[M - D - $\left.\mathrm{H}_{2} \mathrm{O}-\mathrm{HDO}\right](7 \%), 317$ [M - D - $\left.\mathrm{CO}_{2}\right](18 \%)$, $298\left[\mathrm{M}-\mathrm{D}-\mathrm{HDO}-\mathrm{CO}_{2}\right](37 \%)$, and $279[\mathrm{M}-\mathrm{D}-$ $2 \mathrm{HDO}-\mathrm{CO}_{2}$ ] (8\%) from MS/MS of $\mathrm{O}, \mathrm{O}, \mathrm{O}-\mathrm{d}_{3}-\mathrm{PD} 1$, respectively. They are further confirmed by ions in 

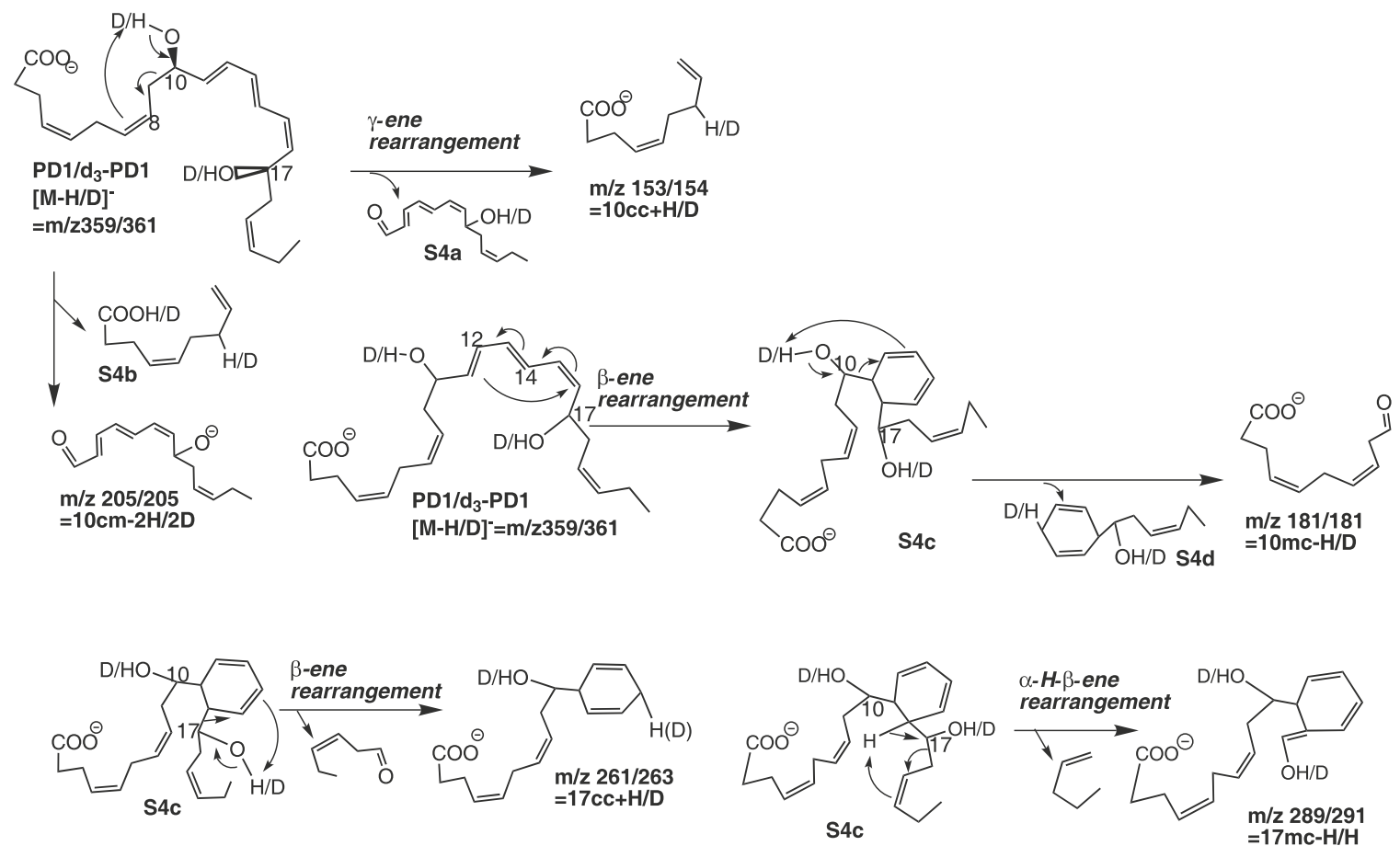

Scheme 4. Fragmentation mechanisms for PD1/d3-PD1 $\left([M-H / D]^{-}=m / z ~ 359 / 361\right)$.

MS/MS of $\mathrm{d}_{5}$-PD1 (21,21,22,22,22- $\mathrm{d}_{5}$-PD1) at $\mathrm{m} / \mathrm{z} 346$ $\left[\mathrm{M}-\mathrm{H}-\mathrm{H}_{2} \mathrm{O}\right](100 \%), 328\left[\mathrm{M}-\mathrm{H}-2 \mathrm{H}_{2} \mathrm{O}\right](13 \%), 320$ $\left[\mathrm{M}-\mathrm{H}-\mathrm{CO}_{2}\right](23 \%), 302\left[\mathrm{M}-\mathrm{H}-\mathrm{H}_{2} \mathrm{O}-\mathrm{CO}_{2}\right](27 \%)$, and $284\left[\mathrm{M}-\mathrm{H}-2 \mathrm{H}_{2} \mathrm{O}-\mathrm{CO}_{2}\right](6 \%)$, respectively; and along with ions from MS/MS of $\mathrm{d}_{8}$-PD1 $\left(\mathrm{O}, \mathrm{O}, \mathrm{O}, 21,21,22,22,22-\mathrm{d}_{8}-\mathrm{PD} 1\right)$ at $\mathrm{m} / \mathrm{z} 348[\mathrm{M}-\mathrm{D}-$ $\left.\mathrm{H}_{2} \mathrm{O}\right](100 \%), 329$ [M - D - $\mathrm{H}_{2} \mathrm{O}-\mathrm{HDO}$ ] (30\%), 322 [M $-\mathrm{D}-\mathrm{CO}_{2}$ ] $(41 \%), 304\left[\mathrm{M}-\mathrm{D}-\mathrm{H}_{2} \mathrm{O}-\mathrm{CO}_{2}\right](35 \%)$, and $284\left[\mathrm{M}-\mathrm{D}-2 \mathrm{HDO}-\mathrm{CO}_{2}\right](3 \%)$, respectively. It is interesting that some of the water loss was as $\mathrm{H}_{2} \mathrm{O}$ rather than HDO. Loss of $\mathrm{HDO}$ is expected for $\mathrm{d}_{3}-\mathrm{PD} 1$ because $\mathrm{D}$ has replaced every hydroxy $\mathrm{H}$. $\mathrm{D}$ in the deuteroxy group exchanged with the hydrogen on the carbon chain when the $[M-D]^{-}$ion of $d_{3}$-PD1 was selected and activated for the MS/MS fragmentation in the ion trap, similar to $\mathrm{d}_{4}$-RvD1 (see above). The MS/MS chain-cut ions and the formation mechanisms are shown in Figure 2 and Scheme 4. Those ions formed via loss of $\mathrm{H}_{2} \mathrm{O}$ from $\mathrm{d}_{3}$-PD1 also manifest the exchange of deuteroxy deuterium with carbon-chain-bonded hydrogen.

The MS/MS ion $m / z 153$ of PD1 is consistent with the fragmentation mechanism of a $\gamma$-ene rearrangement: when the $10-\mathrm{OH} \mathrm{H}$ shifts to the $\mathrm{C} 7$ at $\gamma$ double bond C7,8 through a 6-membered ring, a carbonyl group forms (in S4a) and the C9,10 allylic single bond, at $\alpha$-position to $10-\mathrm{OH}$, cleaves, yielding the ion at $m / z 153$ in MS/MS of PD1 (11\%) and $\mathrm{d}_{5}$-PD1 (7\%). The equivalent ion is at $m / z 154$ for $\mathrm{d}_{3}-\mathrm{PD} 1(7 \%)$ and $\mathrm{d}_{8}-\mathrm{PD} 1(5 \%)$. Ions $m / z 153$ and 154 are equal to $[10 \mathrm{cc}+\mathrm{H}$ from $10-\mathrm{OH}]$ (for PD1 and $\mathrm{d}_{5}-\mathrm{PD} 1$ ) and $[10 \mathrm{cc}+\mathrm{D}$ from 10-OD] (for $\mathrm{O}, \mathrm{O}, \mathrm{O}-\mathrm{d}_{3}-\mathrm{PD} 1$ and $\mathrm{d}_{8}-\mathrm{PD} 1$ ), respectively. If additionally the $17-\mathrm{OH} \mathrm{H}$ or $17-\mathrm{OD} \mathrm{D}$ shifts to the carboxyl anion, it yields the neutral molecule S4b and ion $m / z 205$, equal to [10 $\mathrm{cm}-2 \mathrm{H}$ from hydroxys] for PD1 $(7 \%)$ or $\left[10 \mathrm{~cm}-2 \mathrm{D}\right.$ from deuteroxys] for $\mathrm{d}_{3}$-PD1 (7\%). Its equivalent ion is at $m / z 210(6 \%)$ for $d_{5}$-PD1. The assignment of ions $m / z 205$ and 210 is consistent with ion 187 [205 $-\mathrm{H}_{2} \mathrm{O}$ ] (4\%) of PD1.

Ion $m / z 181$ is equal to [ $10 \mathrm{mc}-\mathrm{H}$ from $\mathrm{OH}$ ] for PD1 $(5 \%)$ and $\mathrm{d}_{5}$-PD1 $(10 \%)$, or to [10 mc - D from OD] for $\mathrm{d}_{8}$-PD1 (29\%) and $\mathrm{d}_{3}$-PD1 (10\%). The corresponding fragmentation mechanism is a charge-remote $\beta$-ene rearrangement with $\alpha-\mathrm{OH}$ as $10-\mathrm{OH}$ and $\beta$-ene as $\mathrm{C} 11,12$ double bond of the parent ion: the conjugated triene $\Delta 11,13,15$ in PD1 forms a six-membered ring in intermediate S4c via the Diels-Alder process, changing the vinyl single bond $\mathrm{C} 10,11$ at position to an allylic single bond (Scheme 4); then the $\mathrm{H}$ from $10-\mathrm{OH}$ moves to $\mathrm{C} 13$ on the newly formed $\gamma$-ene (at $\mathrm{C} 12,13$ ), the allylic single bond $\mathrm{C} 10,11$ breaks, and 10-carbony forms, generating S4d and ion $\mathrm{m} / \mathrm{z} 181$. Additional evidence for the composition of ion $m / z 181$ is ion $m / z 163$ [181 $-\mathrm{H}_{2} \mathrm{O}$ ] $(5 \%)$ in the MS/MS spectrum of PD1 (Figure 2, Scheme 4).

Ion $m / z 261(20 \%)$ in the MS/MS spectra of PD1 is equivalent to $[17 \mathrm{cc}+\mathrm{H}$ from 17-OH] (Scheme 4), generated through a $\beta$-ene rearrangement analogous to the formation mechanism for ion $m / z 277$ from RvD1 (Figure 1 and Scheme 3). When 17-OH H shifts to C14 in S4c, the allylic single bond C16,17 breaks, resulting in a carbonyl group in the neutral loss hexen-3-al and ion $m / z$ 261. This is verified by ion $m / z 263$ from $d_{3}-P D 1$ $(37 \%)$ and $\mathrm{d}_{8}$-PD1 $(15 \%)$, equal to $[17 \mathrm{cc}+\mathrm{D}$ from 17-OD]; and ion $m / z 261$ (23\%) from $\mathrm{d}_{5}$-PD1, equal to [17 $\mathrm{cc}+\mathrm{H}$ from $17-\mathrm{OH}]$. This fragmentation mechanism is 
Table 1. Chain-cut ions and fragmentation mechanisms for low energy MS/MS spectra obtained via CID of electrospray-generated carboxylate anion $\left[\mathrm{M}-\mathrm{H}\right.$ or $\mathrm{D}^{-}$from the LC peak of a mono-HDHA or $\mathrm{O}, \mathrm{O}-\mathrm{d}_{2}-$ mono-HDHA

\begin{tabular}{|c|c|c|c|c|c|c|c|c|c|}
\hline & \multirow[b]{2}{*}{$-\mathrm{HDHA}$} & \multirow[b]{2}{*}{$\begin{array}{l}\text { ion } \\
m / z\end{array}$} & \multirow[b]{2}{*}{ Algorithm } & \multirow[b]{2}{*}{$\mathrm{H}$ is from } & \multirow[b]{2}{*}{$\begin{array}{l}\text { Fragmentation } \\
\text { rearrangement }\end{array}$} & \multicolumn{4}{|c|}{ Confirmation by deuterium-labeling } \\
\hline & & & & & & $\begin{array}{l}\text { labeled- } \\
\text { HDHA }\end{array}$ & $\begin{array}{l}\text { ion } \\
m / z\end{array}$ & Algorithm & $\mathrm{D} / \mathrm{H}$ is from \\
\hline \multirow[t]{7}{*}{$\mathrm{cc}^{\mathrm{a}}$} & $20-$ & 285 & $20 \mathrm{cc}+\mathrm{H}$ & $20-\mathrm{OH}$ & $\beta$-ene & $d_{2}-20-$ & 286 & $20 c c+D$ & $20-O D$ \\
\hline & 17- & 245 & $17 \mathrm{cc}+\mathrm{H}$ & $17-\mathrm{OH}$ & $\beta$-ene & $d_{2}-17-$ & 246 & $17 c c+D$ & $17-O D$ \\
\hline & $16-$ & 233 & $16 c c+H$ & $16-\mathrm{OH}$ & $\gamma$-ene & $d_{2}-16-$ & 234 & $16 c c+D$ & $16-\mathrm{OD}$ \\
\hline & $14-$ & 205 & $14 \mathrm{cc}+\mathrm{H}$ & $14-\mathrm{OH}$ & $\beta$-ene & $d_{2}-14-$ & 206 & $14 c c+D$ & 14-OD \\
\hline & 13- & 193 & $13 c c+H$ & $13-\mathrm{OH}$ & $\gamma$-ene & $d_{2}-13-$ & 194 & $13 c c+D$ & $13-\mathrm{OD}$ \\
\hline & $11-$ & 165 & $11 \mathrm{cc}+\mathrm{H}$ & $11-\mathrm{OH}$ & $\beta$-ene & $d_{2}-11-$ & 166 & $11 c c+D$ & $11-\mathrm{OD}$ \\
\hline & $10-$ & 153 & $10 \mathrm{cc}+\mathrm{H}$ & $10-\mathrm{OH}$ & $\gamma$-ene & $d_{2}-10$ & 154 & $10 c c+D$ & $10-O D$ \\
\hline \multirow[t]{2}{*}{$\mathrm{cm}$} & $11-$ & 177 & $11 \mathrm{~cm}-2 \mathrm{H}$ & $11-\mathrm{OH}, 12 \mathrm{C}$ & $\alpha$-H- $\beta$-ene & $d_{2}-11-$ & 177 & $11 \mathrm{~cm}-\mathrm{D}-\mathrm{H}$ & $\begin{array}{l}11-O D, H \\
\text { from } 12 C\end{array}$ \\
\hline & 8- & 217 & $8 \mathrm{~cm}-2 \mathrm{H}$ & $8-\mathrm{OH}, 9 \mathrm{C}$ & $\alpha$-H- $\beta$-ene & $d_{2}-8-$ & 217 & $8 \mathrm{~cm}-\mathrm{D}-\mathrm{H}$ & $\begin{array}{l}8-O D, H \\
\text { from } 9 C\end{array}$ \\
\hline \multirow[t]{9}{*}{$\mathrm{mc}$} & 17- & 273 & $17 \mathrm{mc}-\mathrm{H}$ & $16 \mathrm{C}$ & $\alpha$-H- $\beta$-ene & $d_{2}-17-$ & 274 & $17 \mathrm{mc}-\mathrm{H}$ & $\mathrm{H}$ from $16 \mathrm{C}$ \\
\hline & $16-$ & 261 & $16 \mathrm{mc}-\mathrm{H}$ & $15 \mathrm{C}$ & $\alpha$-H- $\beta$-ene & $d_{2}-16-$ & 262 & $16 \mathrm{mc}-\mathrm{H}$ & $\mathrm{H}$ from $15 \mathrm{C}$ \\
\hline & $14-$ & 233 & $14 \mathrm{mc}-\mathrm{H}$ & $13 C$ & $\alpha$-H- $\beta$-ene & $\mathrm{d}_{2}-14-$ & 234 & $14 \mathrm{mc}-\mathrm{H}$ & $\mathrm{H}$ from $13 \mathrm{C}$ \\
\hline & $13-$ & 221 & $13 \mathrm{mc}-\mathrm{H}$ & $13-\mathrm{OH}$ & $\beta$-ene & $\mathrm{d}_{2}-13-$ & 221 & $13 \mathrm{mc}-\mathrm{D}$ & $13-O D$ \\
\hline & $11-$ & 193 & $11 \mathrm{mc}-\mathrm{H}$ & $11-\mathrm{OH}$ & $\gamma$-ene & $d_{2}-11-$ & 193 & $11 \mathrm{mc}-\mathrm{D}$ & $11-\mathrm{OD}$ \\
\hline & $10-$ & 181 & $10 \mathrm{mc}-\mathrm{H}$ & $10-\mathrm{OH}$ & $\beta$-ene & $\mathrm{d}_{2}-10$ & 181 & $10 \mathrm{mc}-\mathrm{D}$ & $10-O D$ \\
\hline & 8- & 153 & $8 \mathrm{mc}-\mathrm{H}$ & $8-\mathrm{OH}$ & $\gamma$-ene & $\mathrm{d}_{2}-8-$ & 153 & $8 m c-D$ & 8-OD \\
\hline & 7- & 141 & $7 \mathrm{mc}-\mathrm{H}$ & 7-OH & $\beta$-ene & $\mathrm{d}_{2}-7-$ & 141 & $7 \mathrm{mc}-\mathrm{D}$ & 7-OD \\
\hline & 4- & 101 & $4 \mathrm{mc}-\mathrm{H}$ & 4-OH & $\beta$-ene & $\mathrm{d}_{2}-4-$ & 101 & $4 m c-D$ & 4-OD \\
\hline \multirow[t]{3}{*}{$\mathrm{mm}$} & $11-$ & 149 & $11 \mathrm{~mm}$ & n.a. ${ }^{b}$ & charge-direct & $\mathrm{d}_{2}-11-$ & 149 & $11 \mathrm{~mm}$ & n.a. \\
\hline & 8- & 189 & $8 \mathrm{~mm}$ & n.a. & charge-direct & $\mathrm{d}_{2}-8$ & 189 & $8 \mathrm{~mm}$ & n.a. \\
\hline & 7- & 201 & $7 \mathrm{~mm}$ & n.a. & charge-direct & $\mathrm{d}_{2}-7-$ & 201 & $7 \mathrm{~mm}$ & n.a. \\
\hline
\end{tabular}

ahypothetical homolytic-segment;

${ }^{b}$ not applicable.

further confirmed by ions $\mathrm{m} / \mathrm{z} 217\left[261-\mathrm{CO}_{2}\right]$ and 199 [261 $-\mathrm{H}_{2} \mathrm{O}-\mathrm{CO}_{2}$ ] from both PD1 $(9 \%, 5 \%)$ and $\mathrm{d}_{5}-\mathrm{PD} 1$ $(7 \%, 5 \%)$, as well as by ions $\mathrm{m} / \mathrm{z} 219$ [263- $\left.\mathrm{CO}_{2}\right](12 \%)$ and 200 [263 - $\left.\mathrm{HDO}-\mathrm{CO}_{2}\right](9 \%)$ from $\mathrm{d}_{3}$-PD1. Ions $\mathrm{m} / \mathrm{z} 219\left[263-\mathrm{CO}_{2}\right]$ and $201\left[263-\mathrm{H}_{2} \mathrm{O}-\mathrm{CO}_{2}\right]$ from $\mathrm{d}_{8}$-PD1 $(10 \%, 11 \%)$ are also consistent with this mechanism

The formation of ion $\mathrm{m} / \mathrm{z} 289$ of PD1 corresponds to the $\alpha-\mathrm{H}-\beta$-ene rearrangement, which is analogous to that for ion $\mathrm{m} / \mathrm{z} 305$ from RvD1 (Figure 1 and Scheme 3 ), with the shift of $\mathrm{C} 16 \mathrm{H}$ instead of $17-\mathrm{OH} \mathrm{H}$, where $\alpha-\mathrm{OH}$ is $17-\mathrm{OH}$, and $\gamma$-ene is $\mathrm{C} 19,20$ double bond. When $\mathrm{C} 16 \mathrm{H}$ shifts to $\mathrm{C} 20$ in S4c, the allylic single bond $\mathrm{C} 17,18$ cleaves, yielding a pentaene (neutral loss) and ion $\mathrm{m} / \mathrm{z} 289(5 \%)$ with a 17-enol and a six-membered ring (Figure 2, Scheme 4). This fragmentation process was confirmed by ion $\mathrm{m} / \mathrm{z} 289$ from $\mathrm{d}_{5}$-PD1 $(4 \%)$ and ion $\mathrm{m} / z 291$ from $\mathrm{d}_{3}$-PD1 $(9 \%)$ and $\mathrm{d}_{8}$-PD1 (16\%) (Figure 2). Therefore ions $\mathrm{m} / \mathrm{z} 289$ and 291 are equal to [17 mc $-\mathrm{H}$ from C16] of PD1 and $\mathrm{d}_{3}$-PD1, respectively (Figure 2 and Scheme 4). This process was consistent with the chain-plus-peripheralcut ions formed from $\mathrm{m} / \mathrm{z} 289$ and 291 via loss of water or/and $\mathrm{CO}_{2}: 271$ [289- $\left.\mathrm{H}_{2} \mathrm{O}\right], 245$ [289- $\mathrm{CO}_{2}$ ], and $227\left[289-\mathrm{H}_{2} \mathrm{O}-\mathrm{CO}_{2}\right]$ from PD1 $(4 \%, 10 \%, 4 \%)$ and $\mathrm{d}_{5}-\mathrm{PD} 1$ (5\%, 18\%, 4\%); 272 [291 - HDO] (5\%), 247 $\left[291-\mathrm{CO}_{2}\right](23 \%)$, and $228\left[291-\mathrm{HDO}-\mathrm{CO}_{2}\right](4 \%)$ from $\mathrm{d}_{3}-\mathrm{PD} 1 ; 272$ [291 - HDO] (29\%), 247 [291 -
$\left.\mathrm{CO}_{2}\right](47 \%)$, and $229\left[291-\mathrm{H}_{2} \mathrm{O}-\mathrm{CO}_{2}\right](15 \%)$ from $\mathrm{d}_{8}$-PD1.

The stereoisomers of PD1 were obtained through total organic synthesis [26], and are indistinguishable based only on their MS/MS spectra [24] and data not shown. However, most can be separated via reversedphase LC [24]. Their bioactivities were found to depend on their stereo-structures [24].

\section{HDHAs and O,O-d $-d_{2}-H D H$ As (Table 1,} Supplemental Figure 1 (see electronic version of this article), and Scheme 5).

The hydroxy of each mono-hydroxy docosahexaenoic acid (HDHA) reported here is at the $\alpha$ position relative to its conjugated-diene. The electrospray-generated molecular ion for each HDHA eluted from the LC column is at $\mathrm{m} / z 343[\mathrm{M}-\mathrm{H}]$. The peripheral-cut ions from low-energy MS/MS at $\mathrm{m} / \mathrm{z} 343$, generated via neutral losses, are at $m / z 325\left[\mathrm{M}-\mathrm{H}-\mathrm{H}_{2} \mathrm{O}\right], 299[\mathrm{M}-\mathrm{H}-$ $\left.\mathrm{CO}_{2}\right]$, and $281\left[\mathrm{M}-\mathrm{H}-\mathrm{H}_{2} \mathrm{O}-\mathrm{CO}_{2}\right]$. These ions are consistent with ions generated from MS/MS at $m / z 344$ $[\mathrm{M}-\mathrm{D}]$, for any labile-hydrogen-deuterated HDHA (O,O- $\mathrm{d}_{2}$-HDHA or $\mathrm{d}_{2}$-HDHA), namely, $m / z 325[\mathrm{M}-\mathrm{D}$ - $\mathrm{HDO}$ ] or $326\left[\mathrm{M}-\mathrm{D}-\mathrm{H}_{2} \mathrm{O}\right.$ ], 300 [M - D - $\mathrm{CO}_{2}$ ], and $281\left[\mathrm{M}-\mathrm{D}-\mathrm{HDO}-\mathrm{CO}_{2}\right]$ and $282[\mathrm{M}-\mathrm{D}-$ $\left.\mathrm{H}_{2} \mathrm{O}-\mathrm{CO}_{2}\right]$, respectively, where ions $\mathrm{m} / z 326[\mathrm{M}-\mathrm{D}-$ 

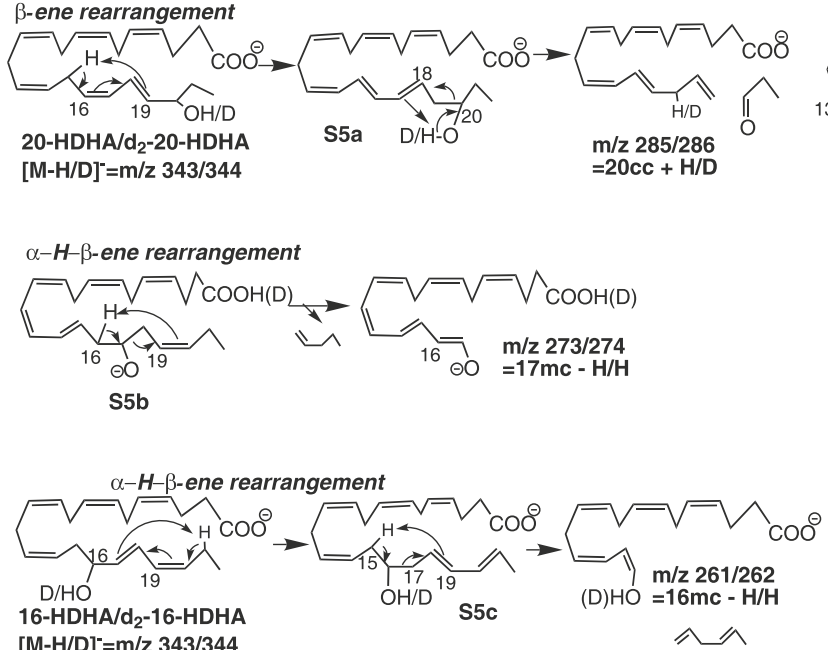

$\beta$-ene rearrangement

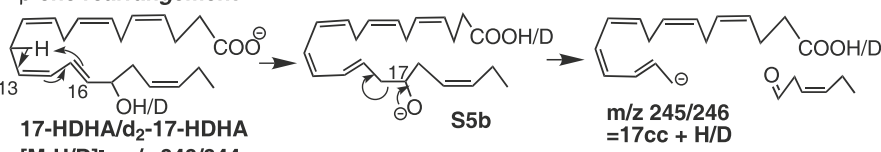
$[\mathrm{M}-\mathrm{H} / \mathrm{D}]^{-}=\mathrm{m} / \mathrm{z} 343 / 344$
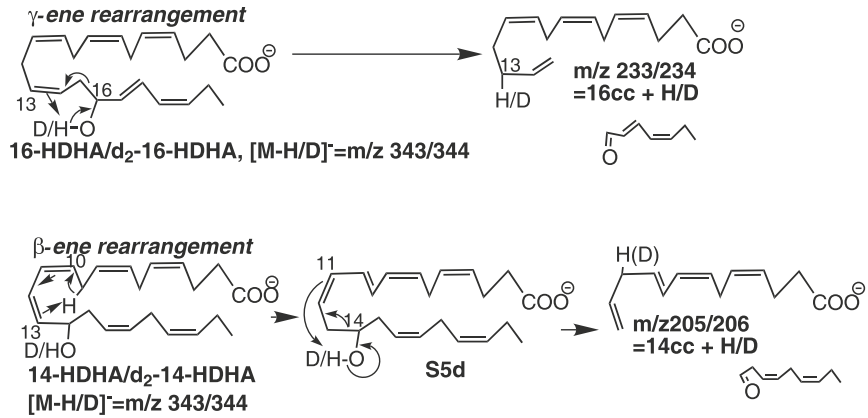
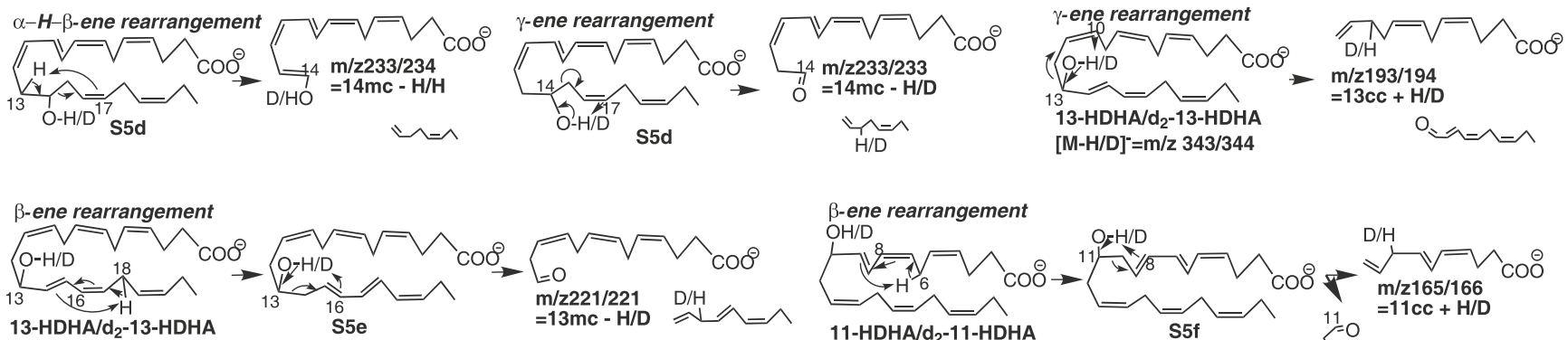

13-HDHA/d 2 -13-HDHA

$[M-H / D]^{-}=m / 2343 / 344$

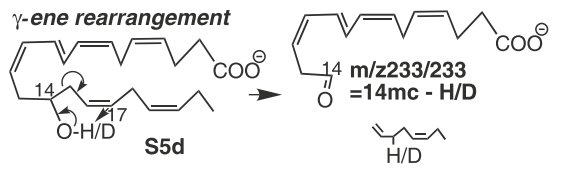

-ene rearrangement

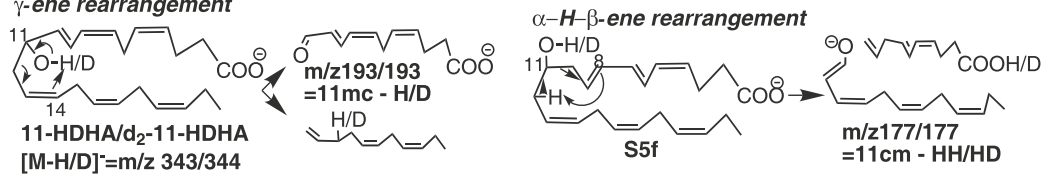

$\beta$-ene rearrangement
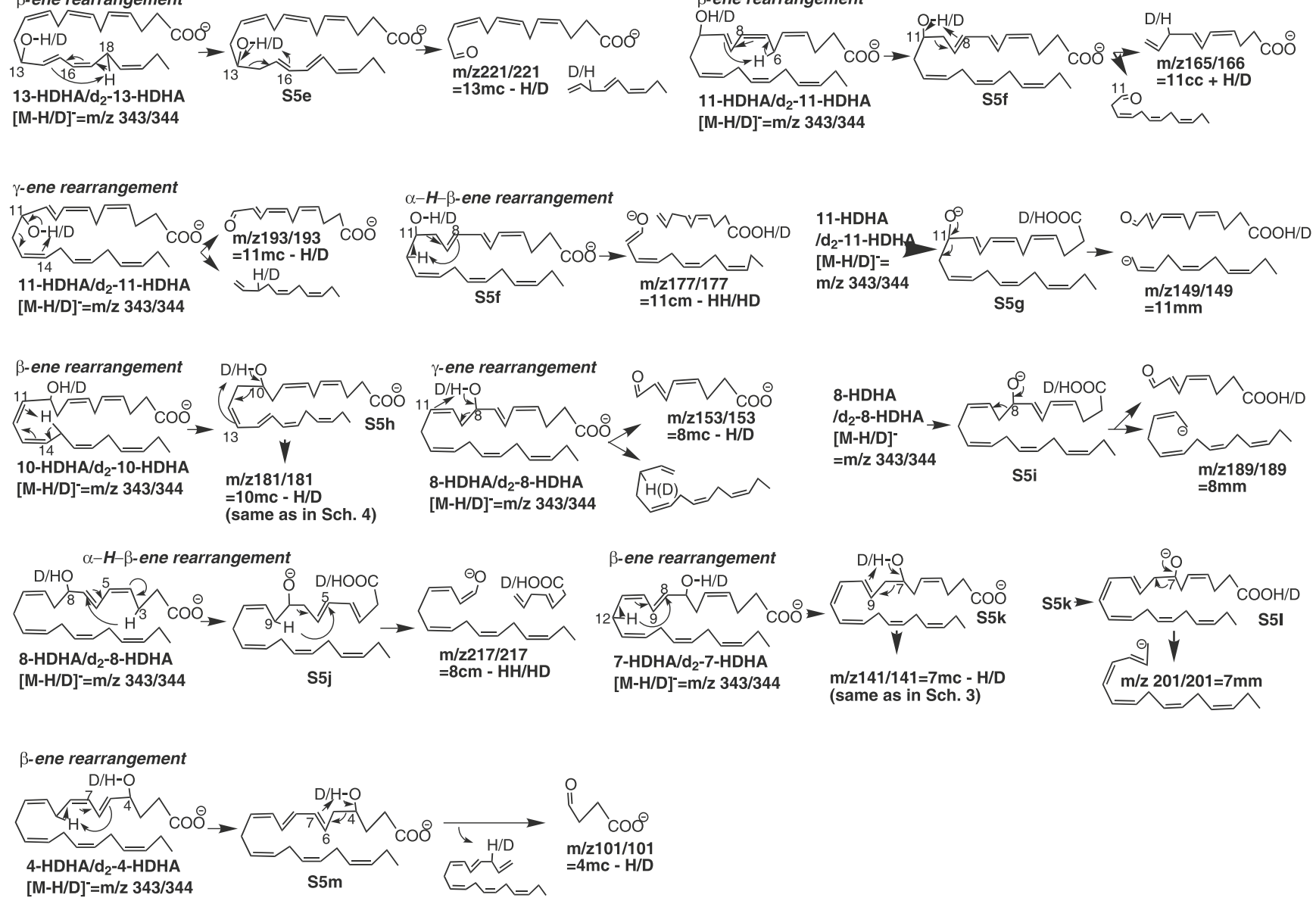

Scheme 5. Fragmentation mechanisms for mono-HDHA/d2-HDHA $\left([\mathrm{M}-\mathrm{H} / \mathrm{D}]^{-}=m / z 343 / 344\right)$. 
$\left.\mathrm{H}_{2} \mathrm{O}\right]$ and $282\left[\mathrm{M}-\mathrm{D}-\mathrm{H}_{2} \mathrm{O}-\mathrm{CO}_{2}\right]$ demonstrated that the deuteroxy $\mathrm{D}$ was exchanged with carbon-chain hydrogens before the water loss in MS/MS processes. The LC-UV-MS/MS analysis also showed that the LC peak of each HDHA has an asymmetric band at $\lambda \max$ 233-236 nm in the UV spectrum (data not shown), indicating the presence of a conjugated diene in each HDHA.

20-HDHA and O,O- $d_{2}-20-H D H A$ (Table 1, Supplemental Figure 1 and Scheme 5). The first HDHA eluted from the LC column is 20-HDHA (20-hydroxy- $4 Z, 7 Z, 10 Z$, $13 Z, 16 Z, 18 E$-docosahexaenoic acid). MS/MS ion $\mathrm{m} / \mathrm{z}$ $285(35 \%)$ or $286(50 \%)$ results from segment $20 \mathrm{cc}$, equivalent to [20 $\mathrm{cc}+\mathrm{H}$ from 20-OH from 20-HDHA] or [20 cc + D from 20-OD of O,O- $\mathrm{d}_{2}-20-\mathrm{HDHA}$ ], via a $\beta$-ene rearrangement with cleavage of the $\mathrm{C} 19,20$ bond. Before the cleavage of the C19,20 bond, the C15 $\mathrm{H}$ shifts to $\mathrm{C} 19$, and conjugated double bond $\Delta 16,18$ changes to $\Delta 15,17$. Then the $20-\mathrm{OH} \mathrm{H}$ migrates to $\mathrm{C} 17$ (S5a) and the newly-formed allylic single bond C19,20 cleaves.

17-HDHA and O,O- $d_{2}-17-H D H A$ (Table 1, Supplemental Figure 1 and Scheme 5). Ion $m / z 245$ (41\%) is equivalent to $17 \mathrm{cc}$ plus $\mathrm{H}$ from 17-OH of 17-HDHA (17-hydroxy$4 Z, 7 Z, 10 Z, 15 E, 19 Z-$ docosahexaenoic acid). This is further confirmed by ion $m / z 246$ [17 cc + D from 17-OD] $(60 \%)$ from $\mathrm{O}, \mathrm{O}-\mathrm{d}_{2}-17-\mathrm{HDHA}$ (Table 1, Supplemental Figure 1). The migration of $\mathrm{C} 12-\mathrm{H}$ to $\mathrm{C} 16$ leads to the transfer of conjugated double bonds $\Delta 13,15$ to $\Delta 12,14$ in S5b. A 17-alkoxide anion is generated when $17-\mathrm{OH} \mathrm{H}$ (or 17-OD D) shifts to the carboxyl in S5b. The negative charge of the 17-alkoxide anion directs the cleavage of the C16,17 bond, resulting in ion $\mathrm{m} / \mathrm{z} 245$ of 17-HDHA (246 of $\mathrm{d}_{2}$-17-HDHA). This ion also forms through a charge-remote $\beta$-ene rearrangement similar to that for ion $m / z 277$ from RvD1 (Figure 1 and Scheme 3 ) and ion $\mathrm{m} / \mathrm{z} 153$ from PD1 (Figure 2, Scheme 4): the 17-alkoxide in S5b is in 17-OH form, of which the H shifts to C14, then the double bond $\mathrm{C} 14,15$ shifts to $\mathrm{C} 15,16$ and the allylic single bond C16,17 cleaves, resulting in ion $\mathrm{m} / \mathrm{z}$ 245.

An $\alpha-\mathrm{H}-\beta$-ene rearrangement, similar to that for ion $\mathrm{m} / \mathrm{z} 305$ from RvD1 (Figure 1 and Scheme 3 ) and ion $\mathrm{m} / \mathrm{z}$ 289 from PD1 (Figure 2, Scheme 4), also occurs for 17-HDHA: when C16-H shifts to $\mathrm{C} 20$ through a sixmembered ring in S5b, of which the 17-alkoxide anion is also in $17-\mathrm{OH}$ form, the $\mathrm{C} 17,18$ bond cleaves, yielding ion $\mathrm{m} / \mathrm{z} 273$ (54\%) equivalent to [17 $\mathrm{mc}-\mathrm{H}$ from C16]. This ion is equivalent to ion $\mathrm{m} / \mathrm{z} 274[17 \mathrm{mc}-\mathrm{H}$ from C16] $(50 \%)$ from $\mathrm{O}, \mathrm{O}-\mathrm{d}_{2}-17-\mathrm{HDHA}$. Chain-plusperipheral ions, resulting from the above ions via loss of $\mathrm{H}_{2} \mathrm{O}$ and /or $\mathrm{CO}_{2}$, are 201 [245- $\left.\mathrm{CO}_{2}\right](12 \%), 229$ [273 $\mathrm{CO}_{2}$ ] $(19 \%)$, and 255 [273 $-\mathrm{H}_{2} \mathrm{O}$ ] $(13 \%)$ of 17-HDHA; and $202\left[246-\mathrm{CO}_{2}\right](13 \%), 230\left[274-\mathrm{CO}_{2}\right](21 \%)$, and $256\left[274-\mathrm{H}_{2} \mathrm{O}\right](10 \%)$ of $\mathrm{O}, \mathrm{O}-\mathrm{d}_{2}-17-\mathrm{HDHA}$. The appearance of these chain-plus-peripheral ions further confirms the presence of a carboxyl and/or hydroxy in the originating ions.

16-HDHA and O,O- $d_{2}-16-H D H A$ (Table 1, Supplemental Figure 1 and Scheme 5). The ion $m / z 233(85 \%)$ or 234 $(100 \%)$ in the MS/MS spectrum of 16-HDHA (16hydroxy-4Z,7Z,10Z,13Z,17E,19Z-docosahexaenoic acid) or $\mathrm{O}, \mathrm{O}-\mathrm{d}_{2}-16-\mathrm{HDHA}$ is equivalent to [16 $\mathrm{cc}+\mathrm{H}$ from $16-\mathrm{OH}$ of 16-HDHA] or [16 cc $+\mathrm{D}$ from 16-OD of $\left.\mathrm{O}, \mathrm{O}-\mathrm{d}_{2}-16-\mathrm{HDHA}\right]$, respectively. Furthermore, ion $\mathrm{m} / \mathrm{z}$ $261(60 \%)$ or $262(35 \%)$ is equivalent to [ $16 \mathrm{mc}-\mathrm{H}$ from C15]. When $\mathrm{H}$ from 16-OH shifts to C13 in 16-HDHA, the $\mathrm{C} 15,16$ allylic single bond cleaves, yielding ion $\mathrm{m} / \mathrm{z}$ 233 in a $\gamma$-ene rearrangement. The same mechanism occurs for $\mathrm{O}, \mathrm{O}-\mathrm{d}_{2}-16-\mathrm{HDHA}$, producing ion $\mathrm{m} / \mathrm{z} 234$. On the other hand, an $\alpha-\mathrm{H}-\beta$-ene rearrangement also takes place: the $\mathrm{C} 21 \mathrm{H}$ migrates to $\mathrm{C} 17$ and conjugated double bonds $\Delta 17,19$ convert to $\Delta 18,20$ in S5c; then the $\mathrm{C} 15 \mathrm{H}$ shifts to C19 and the C16,17 allylic single bond in S5c cleaves, generating ion $\mathrm{m} / \mathrm{z} 261$ for 16-HDHA or 262 for O,O- $\mathrm{d}_{2}-16-\mathrm{HDHA}$ (Scheme 5). Chain-plus-peripheral ions $\mathrm{m} / \mathrm{z} 189$ [233 $-\mathrm{CO}_{2}$ ] (9\%) of 16-HDHA and 190 [234 - $\mathrm{CO}_{2}$ ] $(5 \%)$ of $\mathrm{O}, \mathrm{O}-\mathrm{d}_{2}-16-\mathrm{HDHA}$ are consistent with the formation mechanism for ions $[16 \mathrm{cc}+\mathrm{H}$ from $\mathrm{OH}$ of 16-HDHA] or $[16 \mathrm{cc}+\mathrm{D}$ from $\mathrm{OD}$ of $\left.\mathrm{O}, \mathrm{O}-\mathrm{d}_{2}-16-\mathrm{HDHA}\right]$.

14-HDHA and O,O-14- $d_{2}-H D H A$ (Table 1, Supplemental Figure 1 and Scheme 5). Ions $\mathrm{m} / \mathrm{z} 205$ (34\%) and 233 $(87 \%)$ are equivalent to $[14 \mathrm{cc}+\mathrm{H}]$ and $[14 \mathrm{mc}-\mathrm{H}]$, respectively, from 14-HDHA (14-hydroxy-4Z,7Z,10Z, 12E,16Z,19Z-docosahexaenoic acid). The former corresponds to ion $\mathrm{m} / \mathrm{z} 206(68 \%$, equivalent to [14 $\mathrm{cc}+\mathrm{D}$ from 14-OD]) in $\mathrm{O}, \mathrm{O}-14-\mathrm{d}_{2}-\mathrm{HDHA}$, and the latter is consistent with ions $\mathrm{m} / \mathrm{z} 233$ (93\%, equivalent to [14 mc - D from 14-OD]) and 234 (97\%, equivalent to [14 mc $\mathrm{H}$ from C13]) in $\mathrm{O}, \mathrm{O}-14-\mathrm{d}_{2}-\mathrm{HDHA}$ (Table 1, Supplemental Figure 1). Thus the $\mathrm{H}$ for $[14 \mathrm{cc}+\mathrm{H}]$ was from 14-OH (Scheme 5); and the $\mathrm{H}$ for $[14 \mathrm{mc}-\mathrm{H}]$ was from both $\mathrm{C} 13$ and 14- $\mathrm{OH}$, indicating the involvement of two competing fragmentation mechanisms.

Ion $m / z 205$ forms through a $\beta$-ene rearrangement with the cleavage of the $\mathrm{C} 13,14$ bond and shift of $14-\mathrm{OH}$ $\mathrm{H}$ to $\mathrm{C} 11$ in S5d, which results from migration of $\mathrm{C} 9 \mathrm{H}$ to $\mathrm{C} 13$ and conversion of conjugated double bonds $\Delta 10,12$ to $\Delta 9,11$. When $\mathrm{C} 13 \mathrm{H}$ in S5d shifts to $\mathrm{C} 17$ through an $\alpha$-H- $\beta$-ene rearrangement, the resulting ion is at $m / z 233$ for 14-HDHA or 234 for $\mathrm{O}, \mathrm{O}-\mathrm{d}_{2}-14-\mathrm{HDHA}$. Meanwhile, ion $m / z 233$ also forms for both isotopomers through a $\gamma$-ene rearrangement when $14-\mathrm{OH} \mathrm{H}$ in 14-HDHA or 14-OD D in O,O-d ${ }_{2}-14-\mathrm{HDHA}$ shifts to C17, generating a carbonyl and breaking the C14,15 allylic single bond. The existence of carboxyl and/or hydroxy groups in these four ions is further confirmed by ions $\mathrm{m} / \mathrm{z} 161\left[205-\mathrm{CO}_{2}\right](13 \%), 189$ [233 $\left.-\mathrm{CO}_{2}\right]$ $(7 \%)$, and 215 [233 $\left.-\mathrm{H}_{2} \mathrm{O}\right](4 \%)$ of 14-HDHA and 162 [206 $\left.-\mathrm{CO}_{2}\right](11 \%), 216\left[234-\mathrm{H}_{2} \mathrm{O}\right](5 \%)$, and 190 [234 $-\mathrm{CO}_{2}$ ] (15\%) of O,O-d $\mathrm{d}_{2}-14-\mathrm{HDHA}$. 
13-HDHA and O,O-d $d_{2}-13-H D H A$ (Table 1, Supplemental Figure 1 and Scheme 5). The chain-cut ions in the MS/MS spectrum of 13-HDHA (13-hydroxy-4Z,7Z,10Z, 14E,16Z,19Z-docosahexaenoic acid) are at m/z 193 $(34 \%)$ and $221(31 \%)$, equivalent to $[13 \mathrm{cc}+\mathrm{H}]$ and [13 $\mathrm{mc}-\mathrm{H}]$, respectively (Table 1, Supplemental Figure 1). They are consistent with ions $m / z 194$ (50\%, [13 cc + D from 13-OD]) and 221(78\%, [13 mc - D from 13-OD]) in the MS/MS spectrum of $\mathrm{d}_{2}-13-\mathrm{HDHA}$. Therefore, $\mathrm{H}$ in $[13 \mathrm{cc}+\mathrm{H}]$ or $[13 \mathrm{mc}-\mathrm{H}]$ is from $13-\mathrm{OH}$. These ions correspond to the following MS/MS fragmentation mechanisms: through a $\gamma$-ene rearrangement, the $13-\mathrm{OH} \mathrm{H}$ (or 13-OD D) shifts to $\mathrm{C} 10$, and the $\mathrm{C} 12,13$ allylic single bond cleaves, resulting in ion $m / z 193$ for 13-HDHA (194 for 13-d 2 -HDHA); in parallel, through a $\beta$-ene rearrangement the $\mathrm{C} 13,14$ vinyl single bond converts to an allylic single bond in S5e when the $\mathrm{C} 18 \mathrm{H}$ migrates to $\mathrm{C} 14$, then $13-\mathrm{OH} \mathrm{H}$ (or 13-OD D) shifts to C16 in S5e, and the C13,14 bond breaks, generating ion $\mathrm{m} / \mathrm{z} 221$ from both 13-HDHA and 13- $\mathrm{d}_{2}-\mathrm{HDHA}$, equivalent to $[13 \mathrm{mc}-\mathrm{H}]$ and $[13 \mathrm{mc}-\mathrm{D}]$, respectively. Additionally, the chain-plus-peripheral ions $\mathrm{m} / \mathrm{z} 203$ [221 $\left.-\mathrm{H}_{2} \mathrm{O}\right](5 \%)$ and 177 [221 $-\mathrm{CO}_{2}$ ] (8\%) of 13$\mathrm{HDHA}$ as well as ion 177 [221 $-\mathrm{CO}_{2}$ ] $(8 \%)$ of $\mathrm{O}, \mathrm{O}-\mathrm{d}_{2}-$ 13-HDHA further confirm the composition of ion $\mathrm{m} / \mathrm{z}$ 221.

11-HDHA and O,O-d $d_{2}-11-H D H A$ (Table 1, Supplemental Figure 1 and Scheme 5). Ions m/z 165, 177, 193, and 149 in the MS/MS spectrum of 11-HDHA (11-hydroxy4Z,7Z,9E,13Z,16Z,19Z-docosahexaenoic acid) are equivalent to [11 cc $+\mathrm{H}],[11 \mathrm{~cm}-2 \mathrm{H}],[11 \mathrm{mc}-\mathrm{H}]$, and [11 $\mathrm{mm}]$, respectively. The assignments are confirmed by ions $\mathrm{m} / \mathrm{z} 166$ [11 cc $+\mathrm{D}$ from 11-OD], 177 [11 cm - D from 11-OD - H from carbon-chain], 193 [11 mc - D from 11-OD], and 149 [11 $\mathrm{mm}$ ] in the MS/MS spectrum of $\mathrm{O}, \mathrm{O}-\mathrm{d} 2-11-\mathrm{HDHA}$. These indicate the following fragmentation mechanisms in the MS/MS processes: through a $\beta$-ene rearrangement, the $C 10,11$ bond in 11-HDHA changes to an allylic single bond and intermediate S5f forms when C6-H shifts to $\mathrm{C} 10$, then $11-\mathrm{OH}$ $\mathrm{H}$ (or 11-OD D) shifts to $\mathrm{C} 8$ through a 6-membered ring in S5f and the C10,11 allylic single bond cleaves, yielding ion $m / z 165(14 \%)$ for 11-HDHA (or 166 (12\%) for $\mathrm{O}, \mathrm{O}-\mathrm{d}_{2}-11-\mathrm{HDHA}$ ) and an aldehyde; through a $\gamma$-ene rearrangement, $11-\mathrm{OH} \mathrm{H}$ in 11-HDHA or 11-OD D in $\mathrm{d}_{2}$-11-HDHA shifts to $\mathrm{C} 14$, and the $\mathrm{C} 11,12$ allylic single bond cleaves, generating ion $\mathrm{m} / \mathrm{z} 193$ (22\% for 11HDHA, 21\% for $\mathrm{O}, \mathrm{O}-\mathrm{d}_{2}-11-\mathrm{HDHA}$ ) with a carbonyl group; through an $\alpha-\mathrm{H}-\beta$-ene rearrangement, the $\mathrm{C} 12-\mathrm{H}$ shifts to C8 in S5f, the 11-OH H or 11-OD D migrates to the carboxylic group, and the C11,12 bond cleaves, yielding ion $\mathrm{m} / \mathrm{z} 177$ (8\% for 11-HDHA or $7 \%$ for $\mathrm{d}_{2}$-11-HDHA). Additionally, when 11-OH H from 11HDHA and 11-OD D of O,O-d $\mathrm{d}_{2}-11-\mathrm{HDHA}$ shifts to the carboxyl group, an 11-alkoxide anion (S5g) forms and the negative charge directs the cleavage of the C11,12 allylic single bond, producing ion $\mathrm{m} / \mathrm{z} 149$ (26\% for 11-HDHA, $28 \%$ for $d_{2}-11$ HDHA). The composition and formation mechanism for ion $m / z 165$ are further confirmed by ion 121 [165 - $\mathrm{CO}_{2}$ ] (4\%) of 11-HDHA, and those for ion $\mathrm{m} / \mathrm{z} 166$ of $\mathrm{d}_{2}$-11-HDHA are verified by 122 [166 - $\mathrm{CO}_{2}$ ] (4\%) of $\mathrm{d}_{2}-11-\mathrm{HDHA}$.

10-HDHA and O,O-d $-10-H D H A$ (Table 1, Supplemental Figure 1 and Scheme 5). In contrast to the C10,11 bond in 11-HDHA, the C9,10 bond in 10-HDHA (10-hydroxy$4 Z, 7 Z, 11 E, 13 Z, 16 Z, 19 Z-d o c o s a h e x a e n o i c$ acid) is already an allylic single bond as in PD1 (Figure 2 and Scheme 4). It cleaves through a -ene rearrangement when 10-OH H shifts to $\mathrm{C} 7$ and a carbonyl group forms, yielding ion $m / z 153(6 \%)$, which is equivalent to [10 cc $+\mathrm{H}$ from $10-\mathrm{OH}$ ], following the same pathway as that for ion $m / z 153$ from PD1 (Scheme 4), except that the neutral loss here is a 2,4,7,10-tridecatetraenal versus the neutral loss S4a from PD1. This is consistent with ion $m / z 154$ [10 cc + D from 10-OD] (5\%) in the MS/MS spectrum of $\mathrm{O}, \mathrm{O}-\mathrm{d}_{2}-10-\mathrm{HDHA}$. Ion $m / z 153$ in the MS/MS spectra of the 10 series of neuroprostanes is also likely to have been generated through this mechanism although their segment $10 \mathrm{~cm}$ is different from that of PD1 (Figure 2 and Scheme 4) or 10-HDHA [28].

In competition, a $\beta$-ene rearrangement occurs along $10-\mathrm{OH}$ similar to that for ion $m / z 181$ from PD1 (Figure 2 and Scheme 4): the migration of $\mathrm{C} 15 \mathrm{H}$ to $\mathrm{C} 11$ through a six-membered ring converts the $\mathrm{C} 10,11$ vinyl bond to an allylic single bond in S5h; then $10-\mathrm{OH} \mathrm{H}$ in $10-$ HDHA or 10-OD D in O,O- $\mathrm{d}_{2}-10-\mathrm{HDHA}$ shifts to $\mathrm{C} 13$, $10-\mathrm{OH}$ or $10-\mathrm{OD}$ changes to 10 -carbony, and the $\mathrm{C} 10,11$ single bond cleaves, generating ion $\mathrm{m} / \mathrm{z} 181$, equivalent to [10 $\mathrm{mc}-\mathrm{H}$ from $10-\mathrm{OH}$ in $10-\mathrm{HDHA}](13 \%)$ or [10 $\mathrm{mc}-\mathrm{D}$ from $10-\mathrm{OD}$ of $\left.\mathrm{O}, \mathrm{O}-\mathrm{d}_{2}-10-\mathrm{HDHA}\right](37 \%)$.

8-HDHA and O,O-d $d_{2}-8-H D H A$ (Table 1, Supplemental Figure 1 and Scheme 5). The chain-cut ions in the MS/MS spectrum of 8-HDHA (8-hydroxy-4Z,6E,10Z, 13Z,16Z,19Z-docosahexaenoic acid), and O,O-d $\mathrm{d}_{2}-8-$ HDHA are at m/z 153 (10\%, 8\%), 189 (51\%, 22\%), and $217(13 \%, 7 \%)$, which correspond to [8 mc - H/D], [8 $\mathrm{mm}]$, and [8 $\mathrm{cm}-\mathrm{HH} / \mathrm{HD}]$, respectively. Via a -ene rearrangement, the migration of $8-\mathrm{OH} \mathrm{H}$ in 8-HDHA or 8-OD D of $\mathrm{O}, \mathrm{O}-\mathrm{d}_{2}-8-\mathrm{HDHA}$ to $\mathrm{C} 11$ generates 8-carbony, dissociates the $\mathrm{C} 8,9$ allylic single bond, and yields ion $m / z 153$, equivalent to [ $8 \mathrm{mc}-\mathrm{H}$ from $8-\mathrm{OH}$ of 8 -HDHA or $\mathrm{D}$ from $8-\mathrm{OD}$ of $\left.\mathrm{O}, \mathrm{O}-\mathrm{d}_{2}-8-\mathrm{HDHA}\right]$. On the other hand, the migration of $8-\mathrm{OH} \mathrm{H}$ of $8-\mathrm{HDHA}$ or $8-\mathrm{OD} \mathrm{D}$ of $\mathrm{O}, \mathrm{O}-\mathrm{d}_{2}-8-\mathrm{HDHA}$ to the carboxyl anion results in alkoxide anion S5i, of which the negative charge directs the cleavage of the C8,9 allylic single bond, yielding an 8-carbonyl group and ion $\mathrm{m} / z 189$ [8 $\mathrm{mm}$ ]. Ion $\mathrm{m} / \mathrm{z} 217$ is equivalent to $[8 \mathrm{~cm}-2 \mathrm{H}]$ for 8 -HDHA or [ $8 \mathrm{~cm}-\mathrm{HD}]$ for $\mathrm{d}_{2}-\mathrm{HDHA}$, generated through an $\alpha$-H- $\beta$-ene rearrangement: when $\mathrm{C} 3 \mathrm{H}$ migrates to $\mathrm{C} 7$ through a six-membered ring, $\mathrm{C} 7,8$ becomes an allylic single bond in S5j; in the meantime, the 8-OH H or 8-OD D shifts to the carboxyl anion; then the $\mathrm{C} 9 \mathrm{H}$ in S5j shifts to $\mathrm{C} 5$ and the $C 7,8$ bond breaks, yielding ion $m / z 217$ in the 
MS/MS spectrum of 8-HDHA or $\mathrm{O}, \mathrm{O}-\mathrm{d}_{2}-8$-HDHA. After loss of $\mathrm{CO}_{2}$, ion $\mathrm{m} / \mathrm{z} 153$ was transferred to ion $\mathrm{m} / \mathrm{z}$ 109 for 8-HDHA (29\%) or O,O-d $\mathrm{d}_{2}-8$-HDHA (18\%).

7-HDHA and O,O-d ${ }_{2}-7-H D H A$ (Table 1, Supplemental Figure 1 and Scheme 5). The chain-cut ions in the MS/MS spectrum of 7-HDHA (7-hydroxy-4Z,8E,10Z, 13Z,16Z,19Z-docosahexaenoic acid) or O,O-d 2 -7-HDHA are at $m / z 141(13 \%, 18 \%)$ and $201(8 \%, 7 \%)$, which are equivalent to [7 $\mathrm{mc}-\mathrm{H}$ or $\mathrm{D}]$ and $[7 \mathrm{~mm}]$, respectively, and correspond to the following fragmentation mechanisms. The generation of ion $m / z 141$ is via a $\beta$-ene rearrangement: the $\mathrm{C} 12 \mathrm{H}$ shifts to $\mathrm{C} 8$, changing the C7,8 vinyl single bond to an allylic single bond in S5k; then the $\mathrm{H}$ from 7-OH or D from 7-OD in S5k migrates to $\mathrm{C} 10$ and the $\mathrm{C} 7,8$ bond cleaves, yielding ion $m / z 141$. Competitively, the 7-OH H in S5k migrates to the carboxyl, yielding S5l; the negative charge of the 7 -alkoxide anion S5l directs the cleavage of $\mathrm{C} 7,8$ bond, resulting in ion $\mathrm{m} / \mathrm{z} 201$.

4-HDHA and O,O-d ${ }_{2}-4-H D H A$ (Table 1, Supplemental Figure 1 and Scheme 5). The chain-cut ion is $m / z 101$ (14\%) for 4-HDHA (4-hydroxy-5E,7Z,10Z,13Z,16Z,19Zdocosahexaenoic acid) (27\% for $\left.\mathrm{O}, \mathrm{O}-\mathrm{d}_{2}-4-\mathrm{HDHA}\right)$, which is equivalent to $[4 \mathrm{mc}-\mathrm{H}$ from $4-\mathrm{OH}$ of 4-HDHA or D from 4-OD of O,O- $\mathrm{d}_{2}-4-\mathrm{HDHA}$ ] (Table 1, Supplemental Figure 1). It is generated through a $\beta$-ene rearrangement: when $\mathrm{C} 9 \mathrm{H}$ shifts to $\mathrm{C} 5$, the $\mathrm{C} 4,5$ bond changes to an allylic single bond ( $\mathrm{S} 5 \mathrm{~m}$ ); C 4,5 bond in $\mathrm{S} 5 \mathrm{~m}$ cleaves upon the migration of $4-\mathrm{OH} \mathrm{H}$ of 4-HDHA or 4-OD D of $\mathrm{O}, \mathrm{O}-\mathrm{d}_{2}-4-\mathrm{HDHA}$ to $\mathrm{C} 7$, generating ion $\mathrm{m} / \mathrm{z}$ 101.

\section{Identification of HDHAs from Biogenic Samples (Figure 3)}

Based on the above MS/MS spectra of HDHAs, 20-HDHA, 14-HDHA, 11-HDHA, and 10-HDHA were found in human whole blood via LC-UVMS/MS detailed here as well as 17-HDHA found in stroke-injury murine brain tissues. All the peripheralcut ions in these spectra match the ions in the spectra acquired from standard compounds. There are one or two chain-cut ions from $\alpha$-cleavage in these spectra that match the ions in standard spectra (Table 1, Supplemental Figure 1). The LC retention times and UV spectra of each identified mono-HDHA also match those of the corresponding standard compound (data not shown). Additionally, 21,21,22,22,22$\mathrm{d}_{5}$-17S-HDHA ( $\mathrm{d}_{5}-17 S$-HDHA) was identified in the incubation of $d_{5}$-DHA with 15-LO. It has the same position of double bonds and the position of hydroxy as 17-HDHA, except its C21 and 22 were deuterated. In comparison with the MS/MS spectrum of 17HDHA in Table 1, Supplemental Figure 1, the corresponding ions shifted 5 Daltons, e.g., MS/MS ions $m / z 348[\mathrm{M}-\mathrm{H}], 330\left[\mathrm{M}-\mathrm{H}-\mathrm{H}_{2} \mathrm{O}\right], 304[\mathrm{M}-\mathrm{H}-$
$\left.\mathrm{CO}_{2}\right]$, and $286\left[\mathrm{M}-\mathrm{H}-\mathrm{H}_{2} \mathrm{O}-\mathrm{CO}_{2}\right]$, consistent with $\mathrm{d}_{5}$-17S-HDHA. Ions $\mathrm{m} / z 245$ [17 $\left.\mathrm{cc}+\mathrm{H}\right](27 \%), \mathrm{m} / \mathrm{z}$ $273[17 \mathrm{mc}-\mathrm{H}](50 \%), 255\left[273-\mathrm{H}_{2} \mathrm{O}\right](7 \%), 229[273$ $\left.-\mathrm{CO}_{2}\right](32 \%)$, and 201 [245 $\left.-\mathrm{CO}_{2}\right](14 \%)$ revealed that this MS/MS spectrum is of $\mathrm{d}_{5}-17 S-H D H A$. The LC retention time and UV spectrum $(\lambda \max 235 \mathrm{~nm})$ of $d_{5}$-17S-HDHA matched those of 17S-HDHA (data not shown).

\section{7-HpDHA and 21,21,22,22,22-d $-17-H p D H A$} (Figure 4, Scheme 6).

There is a conjugated double bond in 17-HpDHA. Collision-induced dissociation of the molecular ion $\mathrm{m} / \mathrm{z}$ $359[\mathrm{M}-\mathrm{H}]$ from 17-HpDHA generated the peripheralcut ions $m / z 341\left[\mathrm{M}-\mathrm{H}-\mathrm{H}_{2} \mathrm{O}\right.$ ], $323\left[\mathrm{M}-\mathrm{H}-2 \mathrm{H}_{2} \mathrm{O}\right.$ ], $315\left[\mathrm{M}-\mathrm{H}-\mathrm{CO}_{2}\right], 297\left[\mathrm{M}-\mathrm{H}-\mathrm{H}_{2} \mathrm{O}-\mathrm{CO}_{2}\right]$ and 279 $\left[\mathrm{M}-\mathrm{H}-2 \mathrm{H}_{2} \mathrm{O}-\mathrm{CO}_{2}\right]$. The corresponding ions in the MS/MS spectrum of $\mathrm{d}_{5}-17-\mathrm{HpDHA}$ are $346[\mathrm{M}-\mathrm{H}-$ $\mathrm{H}_{2} \mathrm{O}$ ], $328\left[\mathrm{M}-\mathrm{H}-2 \mathrm{H}_{2} \mathrm{O}\right]$, and $320\left[\mathrm{M}-\mathrm{H}-\mathrm{CO}_{2}\right.$ ]. Ions $m / z 245(9 \%)$ and $289(6 \%)$ are equivalent to [17 cc $+\mathrm{H}]$ and [17 $\mathrm{mc}-\mathrm{H}$ ] for 17-HpDHA. Ion $m / z 245$ forms through a-ene rearrangement: 17-hydroperoxyl $\mathrm{H}$ shifts to $\mathrm{C} 14$ in S6a, a dioxirane ring forms on $\mathrm{C} 17$, and the C16,17 bond breaks. Ion $m / z 289$ forms through an $\alpha$-H- $\beta$-ene rearrangement when $\mathrm{C} 16 \mathrm{H}$ in S6a shifts to $\mathrm{C} 20$ and the $\mathrm{C} 17,18$ allylic single bond breaks. Ion 289 further transfers to ions $m / z 253\left[289-2 \mathrm{H}_{2} \mathrm{O}\right](5 \%)$ and 209 [289 - $\left.2 \mathrm{H}_{2} \mathrm{O}-\mathrm{CO}_{2}\right](4 \%)$. The presence of ions $\mathrm{m} / \mathrm{z}$ $245(36 \%)$ and $289(23 \%)$ in the MS/MS spectrum of $\mathrm{d}_{5}-17-\mathrm{HpDHA}$ further confirms this fragmentation mechanisms.

\section{Discussion}

Impact of a Functional Group and Enes on MS/ MS Fragmentation of Different Lipid Mediators

Under the same MS/MS conditions as for RvD1, Lipoxin $\mathrm{A}_{4}$ (5S,6R,15S-trihydroxy-7E,9E,11Z,13E-eicosatetraenoic acid) produces chain-cut ions $m / z 115$ [5 mc - H], m/z 235 [5 mm], and $m / z 251$ [15 cc $+\mathrm{H}][27,29]$, equivalent to ions $m / z 141[7 \mathrm{mc}-\mathrm{H}$ ], $m / z 233$ [7 mm], and $m / z 277$ $[17 \mathrm{cc}+\mathrm{H}]$, respectively, from RvD1 (Figure 1, Scheme 3). This corresponds to the same structure of Lipoxin $A_{4}$ between $\mathrm{C} 5$ and $\mathrm{C} 15$ as that of RvD1 between $\mathrm{C} 7$ and $\mathrm{C} 17$, the conjugated tetraene bracketed by two vicinal hydroxys on the carboxyl (c)-side and one hydroxy on the methyl terminus (m)-side. However the ion $m / z 279$ [15 mc $-\mathrm{H}$ ] was not observed for Lipoxin $\mathrm{A}_{4}$. There is no double bond at $\gamma$ position to $15-\mathrm{OH}$ on the $\mathrm{m}$ side of Lipoxin $\mathrm{A}_{4}$, i.e., in segment $15 \mathrm{~mm}$, to facilitate generation of this ion through an $\alpha-\mathrm{H}-\beta$-ene rearrangement that yields ion [17 mc - H] m/z 305 from RvD1. The same phenomenon was observed for 15-hydroxyeicosatetraenoic acid (15-HETE) versus 17-HDHA and PD1. 15-HETE has no [15 $\mathrm{mc}-\mathrm{H}$ ] ion $(\mathrm{m} / \mathrm{z} 247)$, but 17-HDHA and PD1 have [17 $\mathrm{mc}-\mathrm{H}$ ] ions as $m / z 273$ and 289, respectively. Therefore, ion $[x \mathrm{mc}-\mathrm{H}]$ indi- 


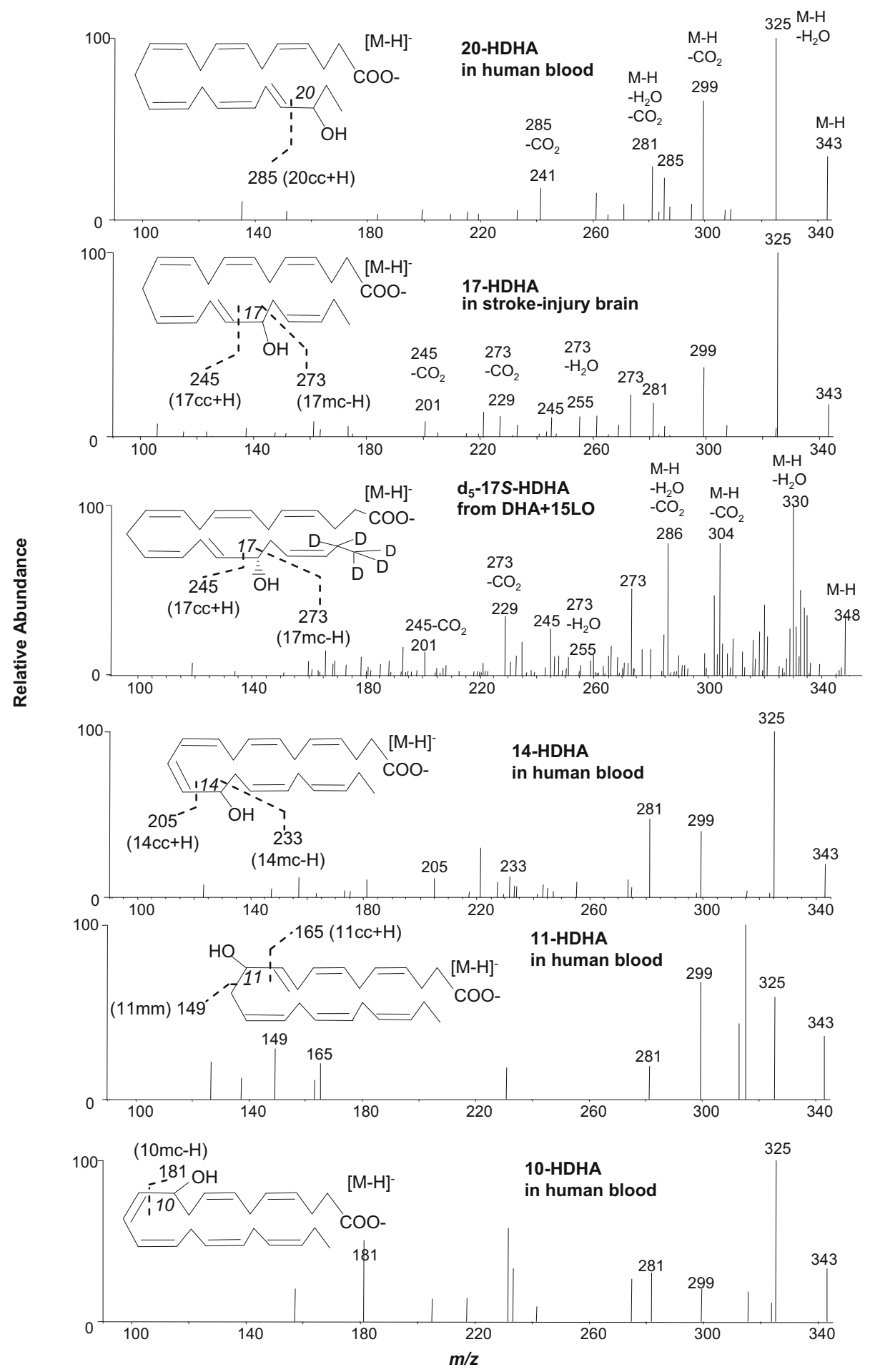

Figure 3. Identification of 20-HDHA, 14-HDHA, 11-HDHA, and 10-HDHA in human blood, 17-HDHA from stroke-injury murine brain tissues, and $21,21,22,22,22-\mathrm{d}_{5}-17 S-\mathrm{HDHA}$ in the incubations of $21,21,22,22,22-\mathrm{d}_{5}$-DHA, and soybean $15-\mathrm{LO}$ as demonstrated with low collision energy MS/MS spectra acquired in the LC-UV-electrospray MS/MS analysis.

cates double bond(s) in $x$ mm segment, with $x$ representing the position of the functional group.

7-HDHA also has the same chain-cut ions as RvD1 does: $[7 \mathrm{mc}-\mathrm{H}]$ and $[7 \mathrm{~mm}]$ around 7-OH (Figure 1, Table 1, Supplemental Figure 1 and Schemes 3 and 5).
The $\gamma$-ene rearrangement for the cleavage of $\mathrm{C} 7,8$ allylic single bond in RvD1 for producing ion $\mathrm{m} / \mathrm{z} 141$ (Scheme 3) is analogous to that for S5k, a transient state of 7-HDHA in MS/MS. However, the shift of C12 H to C8 before such cleavage for 7-HDHA is unnecessary for 


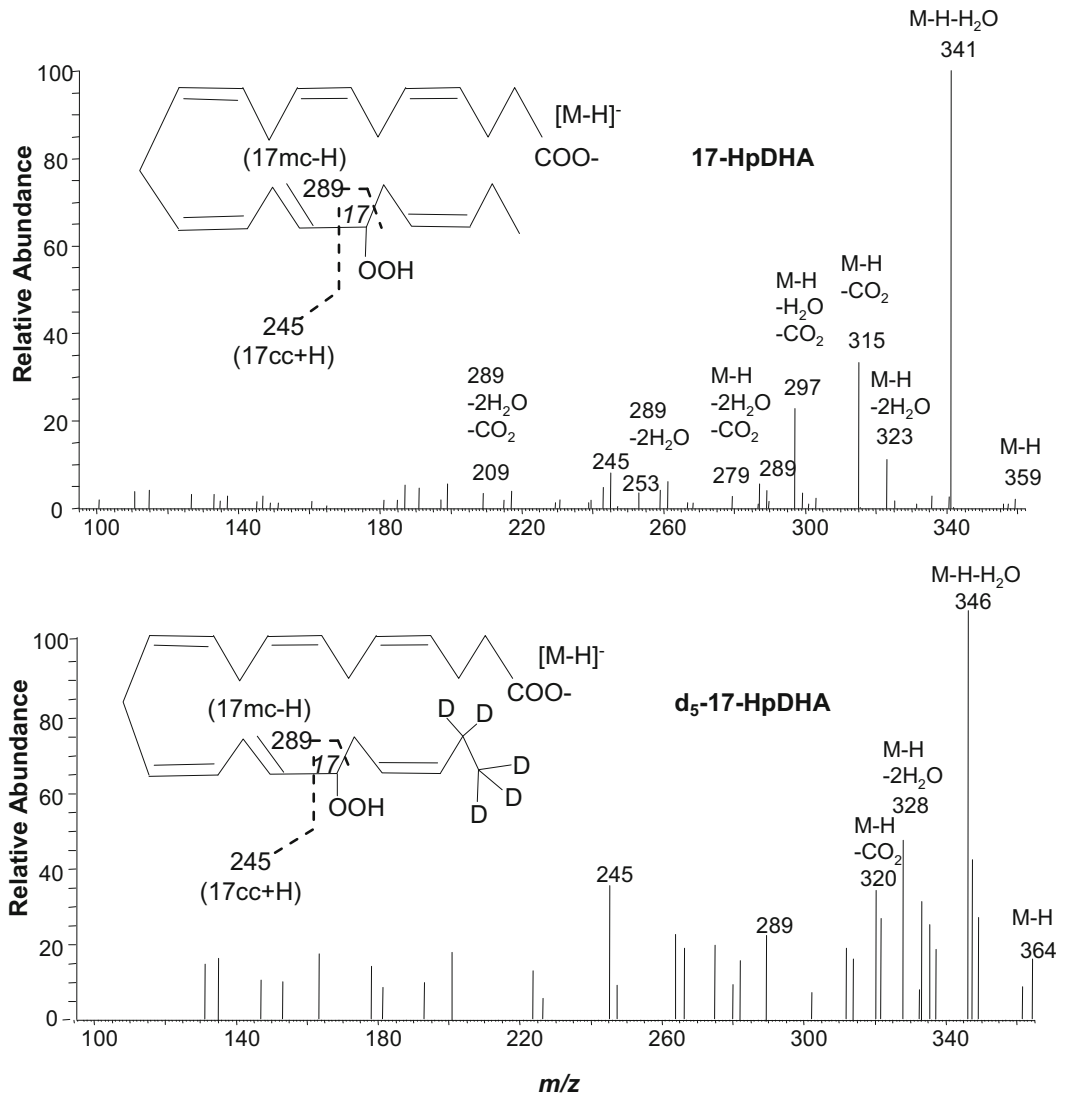

Figure 4. Low-energy MS/MS spectra acquired via CID of electrospray-generated carboxylate anion $[\mathrm{M}-\mathrm{H}]^{-}$from the LC peak of 17-HpDHA and 21,21,22,22,22- $\mathrm{d}_{5}-17-\mathrm{HpDHA}$, which were obtained from isolated-enzyme reactions, as detailed in the Experimental section. Each inset depicts the structure and CID fragmentation.

RvD1 because the $\mathrm{C} 7,8$ bond in RvD1 is already an allylic single bond. The $[7 \mathrm{~mm}]$ ions $\mathrm{m} / \mathrm{z} 233$ and 201 are generated through the same mechanism from RvD1 and 7-HDHA, respectively. Analogously, 5-HETE has the chain-cut ions $\mathrm{m} / \mathrm{z} 115([5 \mathrm{mc}-\mathrm{H}])$ and $203([5 \mathrm{~mm}])$ around 5-OH; this is similar to what $\mathrm{LXA}_{4}$ has $[27,29,30]$.

Although there is an $8-\mathrm{OH}$ in both RvD1 and 8-HDHA, there are no MS/MS ions from RvD1 analogous to ions $[8 \mathrm{~cm}-2 \mathrm{H}],[8 \mathrm{mc}-\mathrm{H}]$, and $[8 \mathrm{~mm}]$ from 8-HDHA (Figure 1, Table 1, Supplemental Figure 1, and Schemes 3 and 5). Because of the 7-OH and the conjugated tetraene 9,11,13,15 of RvD1, the $8 \mathrm{~cm}$ (equal to 7 $\mathrm{mm}$ ) segment of RvD1 is involved in formation of ion $\mathrm{m} / \mathrm{z} 233$ as $7 \mathrm{~mm}$, not as $8 \mathrm{~cm}$, namely, it follows the fragmentation mechanism to produce ion $[7 \mathrm{~mm}]$ instead of $[8 \mathrm{~cm}-2 \mathrm{H}]$. The ion $\mathrm{m} / \mathrm{z} 141$, coming from segment $8 \mathrm{cc}$ (equivalent to $7 \mathrm{mc}$ ) of RvD1, is equivalent to $[7 \mathrm{mc}-\mathrm{H}]$ instead of $[8 \mathrm{cc}+\mathrm{H}]$. RvD1 has the $[8 \mathrm{~mm}$
- H] ion $(m / z 189)$ because the ion can form a conjugated tetranonyl structure to disperse the carbon anion charge for greater stabilization. In contrast, 8-HDHA does not have the $[8 \mathrm{~m} \beta \mathrm{m}-\mathrm{H}]$ ion (would be $\mathrm{m} / \mathrm{z} 174$ ) due to lack of such stabilization.

The structural similarity among 17-HDHA and 17HpDHA is reflected by some common features of their MS/MS spectra (Table 1, Supplemental Figure 1, Figures 3 and 4). The conversion of the C16,17 vinyl single bond to an allylic single bond via shift of $\mathrm{C} 12 \mathrm{H}$ to $\mathrm{C} 16$ is likely to be the first step of the MS/MS fragmentation (Schemes 5 and 6). They all have $[\mathrm{cc}+\mathrm{H}]$ ion $m / z 245$, although the $\mathrm{H}$ is from 17-OH of 17-HDHA and 17$\mathrm{OOH}$ of $17-\mathrm{HpHDHA}$. They all have $[\mathrm{mc}-\mathrm{H}]$ ions with the $\mathrm{H}$ migrating from $\mathrm{C} 16$ to $\mathrm{C} 20$. Such similarity was also observed among 15-HETE, 15-hydroperoxyeicosatetraenoic acid, and 15-oxo-eicosatetraenoic acid $[30,31]$.

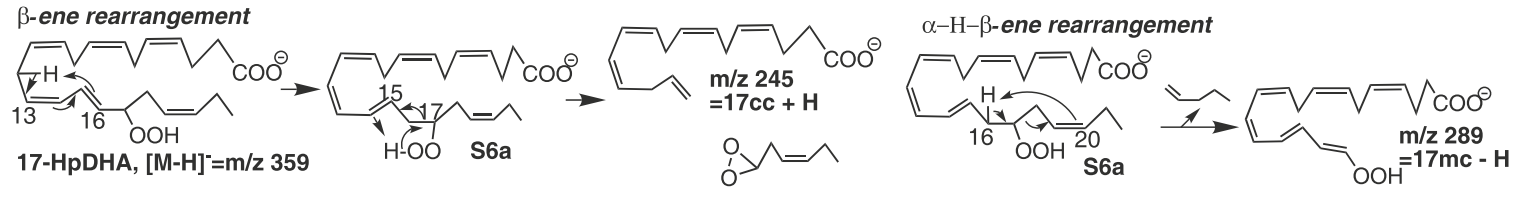

Scheme 6. Fragmentation mechanisms for 17-oxo-DHA $\left([\mathrm{M}-\mathrm{H}]^{-}=m / z 341\right)$. 


\section{$[c c+H]$ Ions in MS/MS of Lipid Mediators}

$[\mathrm{cc}+\mathrm{H}]$ ions are generated with the shift of $\mathrm{H}$ from the hydroxy or hydroperoxy to the $\gamma$ position in segment cc through a $\beta$-ene rearrangement if the segment cc has a $\beta$ double bond, an $\alpha$ vinyl single bond, and an allylic hydrogen (for 20-HDHA and 17-HDHA) or conjugatedtriene (for $17 \mathrm{cc}$ in RvD1 and PD1, 12 cc of $\mathrm{LTB}_{4}$ [19], 15 cc of $\mathrm{LXA}_{4}$ [19] that can facilitate the migration of $\pi$ electrons from the $\beta$ double bond to the $\gamma$-bond and convert the $\alpha$ vinyl single bond to an $\alpha$ allylic single bond. Examples are ions $\mathrm{m} / \mathrm{z} 277$ from RvD1 (Figure 1 and Scheme 3), 261 from PD1 (Figure 2, Scheme 4), 245 from 17-HpDHA (Figure 4 and Scheme 6), 195 from $\mathrm{LTB}_{4}$ and 251 from LXA 427,29$]$, as well as ions 285 from 20-HDHA, 245 from 17-HDHA, 205 from 14HDHA, and 165 from 11-HDHA (Table 1, Supplemental Figure 1 and Scheme 5). These fragmentation processes can also occur through $\gamma$-ene-rearrangement if the cc segment has a $\gamma$ double bond, which is at least the second double bond counted from the carboxyl group (for ion-trap MS/MS, unnecessary for triplequadrupole MS/MS, such as for $8 \mathrm{cc}$ of 8,9-dihydroxyeicosatrienoic acids [27], and an $\alpha$ allylic single bond (Schemes 3 to 6). Examples are ions $\mathrm{m} / \mathrm{z} 153$ from PD1 (Figure 2, Scheme 4), as well as 153 from 10-HDHA, 233 from 16-HDHA, and 193 from 13-HDHA (Table 1, Supplemental Figure 1 and Scheme 5). Additional examples are ions $\mathrm{m} / \mathrm{z} 167$ from 11,12-diHETrE (dihydroxy eicosatrienoic acid), 207 from 14,15-diHETrE, 195 from 5,12-diHETE (dihydroxyeicosatetraenoic acid), 235 from 5,15-dihydroxy-eicosatetraenoic acid, and 221 from lipoxin $\mathrm{B}_{4}[27,29]$.

There is no double bond in $4 \mathrm{cc}$ of 4-HDHA and no allylic hydrogen that can facilitate the migration of the $\pi$ electrons of the $\beta$ double bond to the $\gamma$-bond in $8 \mathrm{cc}$ of 8 -HDHA. The double bond in $7 \mathrm{cc}$ of 7-HDHA and RvD1 is the first double bond counted from the carboxyl group. Therefore these hydroxys have no [cc $+\mathrm{H}]$ ions (for ion-trap mass spectrometer LCQ, ThermoElectron).

\section{[mc - H] Ions in MS/MS of Lipid Mediators}

$[\mathrm{mc}-\mathrm{H}]$ ions are generated with shift of the hydroxy $\mathrm{H}$ to the $\gamma$ position in segment $\mathrm{mm}$, through a $\beta$-ene rearrangement if the $\mathrm{mm}$ has a $\beta$ double bond, an $\alpha$ vinyl single bond, and an allylic hydrogen (for 13HDHA, 10-HDHA, 7-HDHA, and 4-HDHA in Scheme 5) or conjugated-triene (for $10 \mathrm{~mm}$ in PD1) that can facilitate the migration of $\pi$ electrons of the $\beta$ double bond to the $\gamma$-bond and convert the $\alpha$ vinyl single bond to an $\alpha$ allylic single bond. Examples include ions $\mathrm{m} / \mathrm{z}$ 221 from 13-HDHA, 181 from 10-HDHA, 141 from 7-HDHA, and 101 from 4-HDHA (Table 1, Supplemental Figure 1 and Scheme 5), as well as ion $\mathrm{m} / \mathrm{z} 181$ from PD1 (Figure 2, Scheme 4). This process also takes place through $\gamma$-ene-rearrangement if the segment $\mathrm{mm}$ has a $\gamma$-double bond and an $\alpha$ allylic single bond. Examples are ions 141 from RvD1 (Figure 1, Scheme 3), 193 from 11-HDHA, and 153 from 8-HDHA (Table 1, Supplemental Figure 1 and Scheme 5), as well as ions 145 of 5,6-diHETrE, 185 of 8,9-diHETrE, and 115 of both 5,6-diHETE and $\mathrm{LXA}_{4}[27,29,30]$. [mc $\left.-\mathrm{H}\right]$ ions are also produced through an $\alpha-\mathrm{H}-\beta$-ene rearrangement with shift of the $\alpha-\mathrm{H}$ from segment mc to the $\gamma$ position in segment mm whose $\alpha$-bond is a vinyl single bond and $\beta$-bond is a double bond, such as ions $m / z 261$ from 16-HDHA (Table 1, Supplemental Figure 1 and Scheme 5), m/z 305 from RvD1 (Figure 1, Scheme 3), m/z 289 from PD1 (Figure 2, Scheme 4), m/z 233 from 14-HDHA, 273 from 17-HDHA (Table 1, Supplemental Figure 1 and Scheme 5), and $m / z 289$ from 17-HpDHA (Figure 4, Scheme 6).

[cm - 2H] and [mm] Ions in MS/MS of Lipid Mediators

Only three $[\mathrm{cm}-2 \mathrm{H}]$ ions were observed: $\mathrm{m} / \mathrm{z} 205$ from PD1 (Figure 2, Scheme 4), $m / z 177$ from 11-HDHA and $m / z 217$ from 8-HDHA (Table 1, Supplemental Figure 1 and Scheme 5), which are generated through a $\gamma$-ene rearrangement and an $\alpha-\mathrm{H}-\beta$-ene rearrangement, respectively. For PD1, the $17-\mathrm{OH} \mathrm{H}$ was extracted from $\mathrm{cm}$ to $\mathrm{cc}$ by the carboxyl group and $10-\mathrm{OH} \mathrm{H}$ was extracted to $\mathrm{C} 7$ of the cc. For 11-HDHA and 8-HDHA, the $\alpha-\mathrm{H}$ is in segment $\mathrm{cm}$ and is extracted to segment cc that has a $\gamma$-ene (the $\pi$ electrons come from the $\beta$-ene of the molecular ion); the $\mathrm{OH} \mathrm{H}$ is extracted from $\mathrm{cm}$ to $\mathrm{cc}$ by the carboxyl group. The $[\mathrm{mm}]$ ions detected are $\mathrm{m} / \mathrm{z}$ 233 ([7 mm]) from RvD1 (Figure 1, Scheme 3), as well as ions $\mathrm{m} / z 149$ ([11 mm]) from 11-HDHA, 189 ([8 mm]) from 8-HDHA, and 201 ([7 mm]) from 7-HDHA (Table 1, Supplemental Figure 1 and Scheme 5). They are generated through charge-direct fragmentation mechanisms, where the negative charge of the transient alkoxide anion, resulted from extraction of the hydroxy $\mathrm{H}$ by the carboxylic group, directing the cleavage of the $\alpha$ allylic single bond in $\mathrm{mm}$.

\section{Conclusions}

ESI-MS/MS analysis of underivatized ESI-deprotonated molecules of resolvin D1, protectin D1, and other DHAderived products reveals the structures, especially the locations of hydroxy, hydroperoxy, or carbonyl groups, as well as the double bonds. The definitive fingerprints are the CID MS/MS ions formed via cleavage of the carbon chain, namely chain-cut ions. These ions are generated via charge-remote and/or charge-directed fragmentation mechanisms as depicted in Schemes 2 to 6. The CID fragmentation usually consists of several serial and parallel reactions. Each chain-cut ion is equivalent to the corresponding hypothetically homolytic segment (cc, cm, $\mathrm{mc}$, or $\mathrm{mm}$ ) with addition or extraction of up to two protons. Deuterium labeling facilitated the structural analysis of MS/MS ions and the corresponding fragmentation 
mechanisms. The molecular ion structures determine the fragmentation mechanisms, which in turn provide the rationale for the assignment of the MS/MS ion structures, and consequently the molecular ion structures of the DHA-derived compounds. This paper demonstrates a simple approach for comprehensive structure analysis of DHA-derived products without the need for derivatizing the compounds. The fragmentation rules reported here were used for the development of a database and search algorithm for the theoretic MS/MS spectra of novel compounds derived from fatty acids [23].

\section{Acknowledgments}

The authors are very grateful to Professor Andrew F. Rowley's group in the Department of Biological Sciences, University of Wales, Swansea, UK, for providing trout head-kidney and Professor N. Bazan's group in the Louisiana State University Health Sciences Center for providing the stroke-injury murine brain tissues. The authors also thank Jusim Uddin (Core C, P50-DE 016191, Chemistry Department, University of Southern California) for contributions to total organic synthesis. Many thanks to Ms. Mary H. Small, Dr. Barry Torem, and Ms. Stacey Lindberg for assistance with manuscript preparation. This work was supported in part by P50-DE016191 (SH, YL, CNS) and 5R37GM038765 (CNS) from the National Institutes of Health.

\section{References}

1. Gruppo Italiano per lo Studio della Streptochinasi nell'Infarto Miocardico (GISSI)-Prevenzione Investigators. Dietary Supplementation with n-3 Polyunsaturated Fatty Acids and Vitamin E After Myocardial Infarction: Results of the GISSI-Prevenzione Trial. Lancet 1999, 354, 447-455.

2. Freedman, S. D.; Blanco, P. G.; Zaman, M. M.; Shea, J. C.; Ollero, M.; Hopper, I. K.; Weed, D. A.; Gelrud, A.; Regan, M. M.; Lapostata, M.; Alvarez, J. G.; O'Sullivan, B. P. Association of Cystic Fibrosis with Abnormalities in Fatty Acid Metabolism. N. Engl. J. Med. 2004, 350, 560-569.

3. Teitelbaum, J. E. Walker, W. A. The Role of $\omega$-3 Fatty Acids in Intestinal Inflammation. J. Nutr. Biochem. 2001, 12, 21-32.

4. Bazan, N. G. Nestle Nutrition Workshop Series 1992, 28, 121-133.

5. Serhan, C. N.; Hong, S.; Gronert, K.; Colgan, S. P.; Devchand, P. R.; Mirick, G.; Moussignac, R. L. Resolvins: A Family of Bioactive Products of $\omega-3$ Fatty Acid Transformation Circuits Initiated by Aspirin Treatment that Counter Proinflammation Signals. J. Exp. Med. 2002, 196, 1025-1037.

6. Hong, S.; Gronert, K.; Devchand, P. R.; Moussignac, R. L.; Serhan, C. N. Novel Docosatrienes and 17S-Resolvins Generated from Docosahexaenoic Acid in Murine Brain, Human Blood, and Glial Cells: Autacoids in Anti-Inflammation. J. Biol. Chem. 2003, 278, 14677-14687.

7. Marcheselli, L. V.; Hong, S.; Lukiw, W. J.; Tian, X. H.; Gronert, K.; Musto, A.; Hardy, M.; Gimenez, J. M.; Chiang, N.; Serhan, C. N.; Bazan, N. G. Novel Docosanoids Inhibit Brain Ischemia Reperfusion-Mediated Leukocyte Infiltration and Proinflammatory Gene Expression. J. Biol. Chem. 2003, 278, 43807-43817.

8. Mukherjee, P. K.; Marcheselli, V. L.; Serhan, C. N.; Bazan, N. G. Neuroprotectin D1: A Docosahexaenoic Acid-Derived Docosatriene Protects Human Retinal Pigment Epithelial Cells from Oxidative Stress. Proc. Natl. Acad. Sci. U.S.A. 2004, 101, 8491-8496.

9. Van Rollins, M.; Murphy, R. C. Autooxidation of Docosahexaenoic Acid: Analysis of Ten Isomers of Hydroxydocosahexanoate. J. Lipid Res. 1984, 25, 507-517.
10. Kim, H. Y.; Salem, N., Jr. Preparation and the Structural Determination of Hydroperoxy Derivatives of Docosahexaenoic Acid and Other Polyunsaturates by Thermospray LC/MS. Prostaglandins 1989, 37, 105-119.

11. Kim, H. Y.; Karanian, J. W.; Shingu, T.; Salem, N., Jr. Stereochemical Analysis of Hydroxylated Docosahexanoates Produced by Human Platelets and Rat Brain Homogenate. Prostaglandins 1990, 40, 473-90.

12. Cheng, C.; Gross, M. L. Applications and Mechanisms of ChargeRemote Fragmentation. Mass Spectrom. Rev. 2000, 19, 398-420.

13. Murphy, R. C.; Fiedler, J.; Hevko J. Analysis of Nonvolatile Lipids by Mass Spectrometry. Chem. Rev. 2001, 101, 479-526.

14. Lee, S. H.; Williams, M. V.; DuBois R. N.; Blair L. A. Targeted Lipidomics Using Electron Capture Atmospheric Pressure Chemical Ionization Mass Spectrometry. Rapid Commun. Mass Spectrom. 2003, 17 , 2168-2176

15. Hsu, F. F.; Turk, J. Charge-Driven Fragmentation Processes in Diacyl Glycerophosphatidic Acids Upon Low-Energy Collisional Activation. A Mechanistic Proposal. J. Am. Soc. Mass Spectrom. 2000, 11, 797.

16. Griffiths, W. J. Tandem Mass Spectrometry in the Study of Fatty Acids, Bile Acids, and Steroids. Mass Spectrom. Rev. 2003, 22, 81-152.

17. Moe, M. K.; Strom, M. B.; Jensen, E.; Claeys, M. Negative Electrospray Ionization Low-Energy Tandem Mass Spectrometry of Hydroxylated Fatty Acids: A Mechanistic Study. Rapid Commun. Mass Spectrom. 2004, 18, 1731-1740.

18. James, P. F.; Perugini, M. A.; O'Hair, R. A. Sources of Artifacts in the Electrospray Ionization Mass Spectra of Saturated Diacylglycerophosphocholines: From Condensed Phase Hydrolysis Reactions to Gas Phase Intercluster Reactions. J. Am. Soc. Mass Spectrom. 2006, 17 384-394.

19. Ham, B. M.; Jacob, J. T.; Keese, M. M.; Cole, R. B. Identification, Quantification, and Comparison of Major Nonpolar Lipids in Normal and Dry Eye Tear Lipidomes by Electrospray Tandem Mass Spectrometry. J. Mass Spectrom. 2004, 39, 1321-1336.

20. Ekroos, K.; Ejsing, C. S.; Bahr, U.; Karas, M.; Simons, K.; Shevchenko, A. Charting Molecular Composition of Phosphatidylcholines by Fatty Acid Scanning and Ion Trap $\mathrm{MS}^{3}$ Fragmentation. J. Lipid Res. 2003, 44 2181-2192.

21. Tomer, K. B.; Crow, F. W.; Gross, M. Location of Double Bond Position in Unsaturated Fatty Acids by Negative Ion MS/MS. J. Am. Chem. Soc. 1983, 105, 5487-5488.

22. Murphy, R. C.; Barkely, R. M.; Berry, K. Z.; Hankin, J.; Harrison, K; Johnson, C.; Krank, J.; McAnoy, A.; Uhlson, C.; Zarini, S. Electrospray Ionization and Tandem Mass Spectrometry of Eicosanoids. Anal. Biochem. 2005, 346, 1-42.

23. Lu, Y.; Hong, S.; Tjonahen, E.; Serhan, C. N. Mediator-Lipidomics: Databases and Search Algorithms for PUFA-Derived Mediators. J. Lipid Res. 2005, 46, 790-802.

24. Serhan, C. N.; Gotlinger, K.; Hong S.; Lu, Y.; Siegelman, J.; Baer T.; Yang R.; Colgan, S. P.; Petasis, N. A. Anti-Inflammatory Actions of Neuroprotectin D1/Protectin D1 and Its Natural Stereoisomers: Assignments of Dihydroxy-Containing Docosatrienes. J. Immunol. 2006, 176, 1848 1859.

25. Hong, S.; Tjonahen, E.; Morgan, E. L.; Yu, L.; Serhan, C. N.; Rowley, A. F. Rainbow Trout (Oncorhynchus mykiss) Brain Cells Biosynthesize Novel Docosahexaenoic Acid-Derived Resolvins and Protectins-Mediator Lipidomic Analysis. Prostaglandins Other Lipid Mediat. 2005, 78 107-116.

26. Yang, R. Synthetic Study of Lipid Mediators; Doctoral thesis, University of Southern California, Los Angeles 2005, 262 pp.

27. Wheelan, P.; Zirrolli, J. A.; Murphy, R. C. Electrospray Ionization and Low Energy Tandem Mass Spectrometry of Polyhydroxy Unsaturated Fatty Acids. J. Am. Soc. Mass Spectrom. 1996, 7, 140-149.

28. Yin, H.; Musiek, E. S.; Gao, L.; Porter, N. A.; Morrow, J. D. Regiochemistry of Neuroprostanes Generated from the Peroxidation of Docosahexaenoic Acid in Vitro and in Vivo. Biol. Chem. 2005, 280, 26600-26611.

29. Chiang, N.; Takano, T.; Clish, C. B.; Petasis, N. A.; Tai, H. H.; Serhan C. N. Aspirin-Triggered 15-epi-LXA 4 Generation by Costimulation of Human Peripheral Blood Cell Types and in a Mouse Acute Pperitonitis Model: Development of a Specific 15-epi-LXA ${ }_{4}$ ELISA. J. Pharmacol. Exp. Ther. 1998, 287, 779-790.

30. http://www.lipidmaps.org/data/classification/fa.html

31. MacMillan, D. K.; Murphy, R. C. Analysis of Lipid Hydroperoxides and Long-Chain Conjugated Keto Acids by Negative Ion Electrospray Mass Spectrometry. J. Am. Soc. Mass Spectrom. 1995, 6, 1190-1201. 